Journal of

Materials Sciences and Applications

\title{
Post Treatment of Hot Dip Galvanized Steel Sheet- Chromating, Phosphating and other Alternative Passivation Technologies
}

\section{P. Saravanan ${ }^{*}$ and S Srikanth}

R\&D Centre for Iron and Steel, Steel Authority of India Limited, Ranchi- 834002 INDIA

${ }^{\star}$ Corresponding author: P. Saravanan, R\&D Centre for Iron and Steel, Steel Authority of India Limited, Ranchi- 834 002 INDIA; Email: sarvan@sail-rdcis.com

Received Date: December 05, 2019 Accepted Date: January 25, 2019 Published Date: January 29, 2019

Citation: P. Saravanan (2019) Post Treatment of Hot Dip Galvanized Steel Sheet- Chromating, Phosphating and other Alternative Passivation Technologies. J Mater sci Appl 3: 1-22.

\begin{abstract}
Zinc coatings protect steel from corrosion in two ways, namely, through barrier and galvanic protection. However, zinc itself undergoes and suffers rapid corrosion under conditions involving high moisture and humidity. Under these conditions, moisture accumulation and/or condensation takes place within the folds of the galvanized coils under storage leading to formation of patches of powdery "white rust" or "storage stains". Therefore, traditionally chemical treatments have been imparted to the hot dip galvanized coils/ sheets to provide the zinc coating with a relatively, shortterm corrosion resistance during the transit to the place of application. Conventionally, chromic acid based treatments (termed "chromating") have been employed in the galvanizing industry to passivate the virgin, hot-dipped zinc coating surface by developing complex, insoluble zinc chromate films superficially. However, with the imposition of stringent environmental regulations on the use and discharge of chromium compounds and effluents, considerable amount of research has been recently devoted, the world over, to find alternative technologies for passivation of hot dip galvanized sheet. Some of such treatments comprise phosphating, molybdating and passivation using silicon-based organofuntional compounds called "silanes" and other proprietary organic chemicals. Although, none of these treatments match the effectiveness and potency of a chromate treatment and the protection afforded by it, still they are seen as potentially viable substitutes for passivation and protection of galvanized sheet against white rust in galvanizing community. Besides, most of these emerging treatments are in a fledgling state of research and their application to continuous galvanizing lines needs to be explored sufficiently for them to be considered as suitable replacements to chromating and to be adopted in a hot dip galvanizing line.

The present paper starts with a brief introduction to the mechanism of corrosion of zinc and the sacrificial protection of steel in hot dip galvanized coatings, following which, it reviews, in some detail, the inorganic chemical treatments such as chromating and phosphating for the passivation of hot dip galvanized steel sheet. The paper also briefly touches upon some of the recently-researched alternative treatments for the protection and corrosion resistance of zinc coatings on steel.
\end{abstract}

C2019 The Authors. Published by the Clerisy under the terms of the Creative Commons Attribution License http://creativecommons.org/licenses/ by/3.0/, which permits unrestricted use, provided the original author and source are credited. 


\section{Introduction}

Steel sheets are galvanized because the coated zinc layer confers sacrificial anode cathodic protection (SACP) to steel besides acting as a physical barrier to the ingress of corrosive constituents such as moisture, oxygen, chlorides, sulphates, etc. to the steel surface. The corrosion resistance or, in other terms, the service life of a galvanized coating is directly proportional to its thickness. As a barrier layer, a continuous zinc coating physically separates the steel from the corrosive environment. On the other hand, by galvanic protection, zinc acts as a sacrificial anode and corrodes preferentially to protect the underlying steel at voids, scratches and cut edges of the coating. The sacrificial properties of zinc can ben seen in a galvanic series where the potential of zinc is less noble than steel in most environments at ambient temperatures. In practice, this means that steel exposed at a coating defect or at a cut edge will not rust until the nearby zinc is consumed [1].

Although zinc affords excellent corrosion protection to steel in a galvanized sheet by means of both barrier and galvanic protection, yet it is itself susceptible to corrosion even in mildly humid and moist environments. Under humid conditions, the zinc surface soon develops patches of a white, powdery corrosion product which is often referred to as "white rust" or a "storage stain". Storage stains are so called because the phenomenon is frequently observed and encountered within the folds of finished galvanized coils/ sheets under storage where moisture accumulation and/or condensation takes place readily.

If the zinc is protected against its own corrosion, then the longevity of the galvanized steel sheet is greatly enhanced. This is where the chemical treatments, termed "passivation" or "conversion" coatings, assume an important role in improving the performance of a hot dip galvanized sheet [2].

\section{Corrosion of Zinc}

Zinc, by its very nature, is a reactive metal and tends to corrode quite readily when exposed to moisture. The atmospheric corrosion resistance of galvanized steel has been monitored for many years in numerous environments. Zinc corrosion has been found to be approximately linear with time and is a function of the average coating weight or its thickness (Figure.1). When zinc corrodes in the presence of air and moisture, it undergoes a series of chemical reactions, changing from metallic zinc on the surface to other chemical compounds. In dry air, newly exposed zinc oxidizes (reacts with oxygen) to form a very thin zinc oxide $(\mathrm{ZnO})$ layer. In the presence of moisture, the zinc oxide reacts further with the water, resulting in the formation of zinc hydroxide $\left[\mathrm{Zn}(\mathrm{OH})_{2}\right]$. Neither of these corrosion products is very protective to the underlying zinc. However, zinc hydroxide can react further with carbon dioxide $\left(\mathrm{CO}_{2}\right)$ from the atmosphere to produce a basic zinc carbonate $\left(\mathrm{ZnCO}_{3}\right)$, which is protective. Thus, over time and under the influence of cyclic weathering, the final corrosion product is zinc carbonate formed by the reaction between zinc hydroxide and carbon dioxide in the air; this manifests as a gray patina normally associated with weathered galvanized coatings. Zinc carbonate is a thin, tenacious, compact, and stable (insoluble in water) film and therefore, acts to impede further corrosion of zinc. When the surface is further exposed to rain or condensation, the protective film serves as a barrier between the moisture and the zinc underneath. It is the presence of this passive film that slows down the reactivity of the zinc, thereby dramatically reducing the corrosion rate of the zinc coating [3].

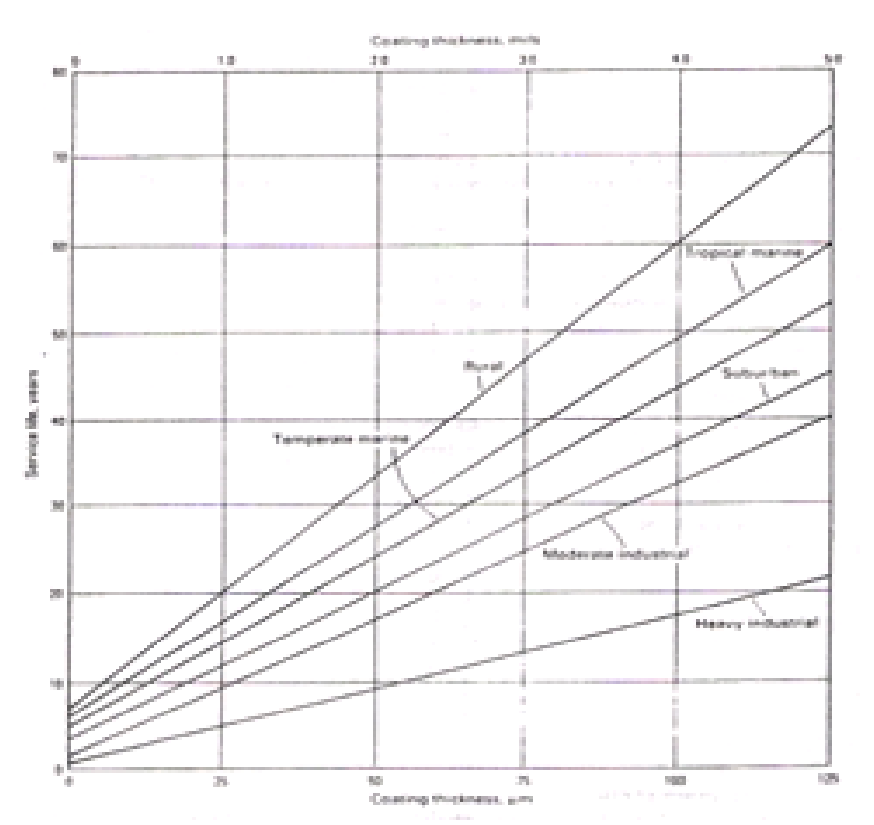

Figure 1: Service life (time to 5\% rusting of steel surface) versus thickness of the coating for various atmospheres

The series of chemical reactions that take place in the atmosphere during the corrosion of zinc in contact with air and moisture can be depicted as given below:

At cathodic sites,

At anodic sites,

$$
\mathrm{O}_{2}+2 \mathrm{H}_{2} \mathrm{O}+4 \mathrm{e}^{-}=4 \mathrm{OH}^{-}
$$

$$
\begin{aligned}
& \mathrm{Zn}=\mathrm{Zn}^{2+}+2 \mathrm{e}^{-} \\
& 2 \mathrm{Zn}+\mathrm{O}_{2}=2 \mathrm{ZnO} \\
& \mathrm{Zn}+2 \mathrm{H}_{2} \mathrm{O}=\mathrm{Zn}(\mathrm{OH})_{2}+\mathrm{H} 2 \\
& \mathrm{ZnO}+\mathrm{H}_{2} \mathrm{O}=\mathrm{Zn}(\mathrm{OH})_{2} \\
& \mathrm{Zn}(\mathrm{OH})_{2}+\mathrm{CO} 2=\mathrm{ZnCO}_{3}+\mathrm{H}_{2} \mathrm{O} \\
& 2 \mathrm{ZnO}+\mathrm{H}_{2} \mathrm{O}+\mathrm{CO}_{2}=2 \mathrm{ZnCO}_{3} \cdot 3 \mathrm{Zn}(\mathrm{OH})_{2}
\end{aligned}
$$

The passive surface film that forms on zinc, while tenacious, is not totally protective and continued corrosion does occur over time. However, because of the nature of the continuous passive film, the corrosion rate is diminished substantially. A key part of the corrosion mechanism is that the surface needs to dry in air in order to develop and maintain the passive layer. It is during the drying part of a rain cycle that the zinc carbonate passive film develops.

When galvanized sheet gets wet, while still in coil 
form, storage stains can result. Storage stain (white rust) is simply the chemical compound, zinc hydroxide, which forms when zinc is in contact with moisture. It does not convert to a zinc carbonate passive film because the tightly packed folds are not freely exposed to carbon dioxide containing air. The protective zinc carbonate film never gets a chance to form. Since the corrosion reaction continues to proceed as long as the surfaces are wet and starved for carbon dioxide, a large accumulation of zinc hydroxide can form.

When white rust does occur, there is an actual loss of zinc coating, and some of the zinc that is intended to protect the coated steel product while in service is lost. The extent of damage is primarily dependent on:

1. the exposure time to moisture,

2. the temperature that is experienced during storage, and

3 . the presence of accelerating corrosive agents, such as chloride-containing salts.

Often, the amount of white rust appears to quite heavy when, in fact, the amount of zinc corroded is small. This occurs because zinc hydroxide is somewhat flocculent, and builds up in the area of wetness. If the application is not aesthetically critical, the galvanized coating should perform very well and meet the requirements and expectations of the end user. In most instances involving outdoor exposure, the white rust will disappear over time, as it is either washed off by rainfall or is converted to zinc oxide and then zinc carbonate. It is also expedient to mention that less severe storage stains (white rust) can be treated to some extent to improve the appearance of galvanized sheet by light brushing with mineral oil and saw dust or by washing with $10 \%$ (by volume) acetic acid solution or $5 \%$ (by volume) phosphoric acid solution followed by neutralizing with water. It is also worthwhile to apply a good, colour-matched zinc-rich paint to the affected areas after the above treatments.

Clearly, it is very desirable to avoid storage stain on galvanized sheet. Often, the customer's application requires the aesthetic appearance of a bright galvanized surface, and no amount of storage stain is acceptable.

\section{Chemical Passivating Treatments}

The best way of minimizing the chances of white rust formation during shipment and storage of galvanized coils/ sheets is the application of a "surface passivation treatment" by the steel sheet manufacturer. This passivation coating is applied on the galvanizing line. It is very thin, and usually invisible, corrosion inhibiting film. The most common type of passivation treatment is a water-based chromate coating. It is applied by spraying a chromate solution onto the surface, or dipping the sheet into a bath containing the solution. After the liquid is applied to the surface, the excess is "squeezed" off using rubber-coated rolls. Following this, the passivating film is dried thoroughly before recoiling the coated sheet at the exit end of the galvanizing line. The solution, by chemical reaction with zinc, forms a thin corrosion inhibiting, sparingly soluble and electrically insulating film of insoluble chromates that re- tards oxidation of zinc efficiently, although there is a limit on their protective action. The film is essentially a superficial layer containing a complex mixture of chromium compounds. These clear passivation coatings have been in use for many years, and their performance is exceptional with respect to minimizing the tendency for staining when the sheets get wet as coils or bundles. Steel sheet manufacturers use the term "passivation treatment" or "chemical treatment" interchangeably for the process. However, it is important to note that the mill-applied passivation treatments only minimize the tendency for storage stain; they do not eliminate its occurrence if the product is subjected to very adverse conditions. The passivation treatment also helps maintain the bright, shiny appearance of a galvanized sheet for a longer time under conditions of outdoor exposure. The surface also dulls in a more uniform fashion if the sheets are passivated [4].

The chromate solutions contain mixtures of hexavalent and trivalent chromium compounds, nitric acid, and proprietary additives to impart colour. As such, freshly deposited chromate films are gelatinous mixtures of chromium hydroxides and oxides. Upon drying, the chromate films may crack due to tensile stresses set up in the chromate films as a result of volume shrinkage. The heat resistance of many chromates can be improved by the use of suitable organic and inorganic sealers. Chromates on zinc can vary in colour from an almost colourless, blue-white appearance, commonly referred to as single dip blue, through the yellow iridescent shades, to the heavy olive drab and black types. The coatings are usually applied by immersion; although spraying, brushing, swabbing, or electrolytic methods are also used. The appearance of the chromate film can vary depending on the formulation of the bath, basis metal and process parameters. The films can be modified from thin, clear-bright to the thicker, yellow iridescent, to the heaviest brown, olive drab and black films. Most chromate films are soft and gelatinous when freshly formed. Once dried, they slowly harden or set with age and become hydrophobic, less soluble, and more abrasion resistant. Variegated colours are normally obtained on chromating and are due mainly to interference colours of the thinner films and to the presence of the chromium compounds in the films. Since the widest range of treatments available is for zinc, coatings for this metal afford an excellent example of how colour varies with film thickness. The clear-bright and blue-bright, being the thinnest coatings, may show interference hues ranging form red, purple, blue, green to a trace of yellow, especially when viewed against a white background. Next, in the order or increasing thickness, come the iridescent yellows, browns, bronzes, olive drabs and blacks. Physical variations in the metal surface also affect the apparent colour of the coated surface [4-6].

Chromate passivation can provide exceptionally good corrosion resistance, depending upon the basis metal, the treatment used and the film thickness. Protection is due both to the corrosion inhibiting effect of hexavalent chromium contained in the film and to the physical barrier presented by the film itself. Even scratched or abraded films retain a great deal of their protective value, since the hexavalent chromium 
content is slowly leachable in contact with moisture, providing a self healing effect. The degree of protection is normally proportional to film thickness. Therefore, thin, clear coatings provide the least corrosion protection; the light iridescent coatings form an intermediate group, while the heavy olive drab to brown coatings result in maximum corrosion protection. The coatings are particularly useful in protecting metal against oxidation due to highly humid storage conditions, exposure to marine atmospheres, handling or fingerprint marking, and other conditions which normally cause corrosion of metal.

The films in most common use are formed by the chemical reaction of hexavalent chromium with a metal surface in the presence of other components, or activators in the acid solution. The hexavalent chromium is partially reduced to trivalent chromium during the reaction, with a concurrent rise in the $\mathrm{pH}$, forming a complex mixture consisting largely of hydrated basic chromium chromate and hydrous oxides of both chromium and the basis metal. The composition of the film is rather indefinite, since it contains varying quantities of the reactants, reaction products and water of hydration, as will as the associated ions of the particular systems. There are a number of factors which affect both the quality and the rate of formation of chromate films, some of which will be discussed subsequently.

\section{Passivating Oils}

Besides the use of chromate chemical passivation treatments, other surface treatments can be used. The most common are rust-inhibitive oils. These are oils containing corrosion inhibitors that provide protection from storage stains. The oil serves as the carrier solution for the inhibitor. As with chromate treatments, the oil is applied by the steel sheet manufacturer on the galvanizing line. A common method of applying the oil is by an electrostatic applicator. These oils are not intended to provide sufficient lubrication for applications such as deep drawing, but they do provide some lubrication and can assist with some forming operations. Another type of oil is "vanishing oil". It is a volatile compound that evaporates when exposed to air, and leaves behind a corrosion inhibitor on the sheet surface [5].

Often, the end use defines whether a chromate passivation treatment or rust-inhibitive oil should be applied. Typically, when the end use is one that does not involve painting or spot welding, the chromate passivation method is the better option. If the application requires painting, a rust-inhibitive oil is usually the best. Besides the use of oils or chemical treatments, there are other ways to minimize the tendency for storage stain. A common method involves wrapping the coil in a packaging material which may have a corrosion inhibitor impregnated into it to provide even better protection.

\section{Chromating \\ Definition and general description of the process}

The term "chromating" applies to the chemical or electrochemical treatment of metals and metallic coatings in solutions containing chromic acid $(\mathrm{H} 2 \mathrm{CrO} 4)$, chromates or dichromates as the main constituents. As a result of such treatment, a protective conversion coating is produced on the metal surface composed of tri- and hexavalent chromium compounds. The metal corrosion inhibiting properties of chromates are well known. Small amounts of these substances added to circulating water systems passivate the metal surface and hence prevent corrosion. The chromate coatings result in deposition of insoluble compounds on the metal surfaces through one or more of the following mechanisms: [7]

- Chromates, being strongly oxidizing agents in acidic solutions; may promote the formation of insoluble salts on the metal surface or increase the thickness of natural oxide films. - Products of reduction of chromic acid are usually insoluble, as for example chromium trioxide (Cr2O3).

- Metal chromates are often insoluble (for instance zinc chromate).

- Chromates may take part in a number of complex reactions, particularly in the presence of certain additives, giving deposits of mixed compounds including ions of the treated metal.

The main reasons for chromating may include one or more of the following:

- Raising the corrosion resistance of the metal or metallic protective coating; in the latter case this may concern prolongation of the time in which the first corrosion sites appear both on the coating metal and on the basis metal.

- Decreasing the surface liability to finger-marking.

- Increasing adhesion of paint or other organic coatings.

- Obtaining colour or decorative effects.

Chromate coatings can be applied by both chemical and electrochemical methods. They can be deposited as either singular, compact coatings on a clean metal surface or as coatings supplementing the protective action of other types of coatings such as oxides or phosphate coatings. Chromating offers simplicity of operation, short time of treatment, easy availability and low prices of chemicals and finally, the specific properties of the coatings produced. The corrosion resistance of the chromate coatings is believed to be higher than that of phosphate coatings. The corrosion resistance and other properties of chromate coatings depend on the basis metal, its surface structure and method of surface preparation; the treatment solution, its chemical composition, temperature and $\mathrm{pH}$; time of immersion; the course of the chromating process itself; post-drying conditions and possibly the additional treatment of the chromate coatings obtained, e.g. applying oil or a paint coating. In the case of chromate coatings obtained by electrochemical methods, the current density plays an important role [8].

As mentioned previously, chromate films are chemical conversion coatings. The substrate metal participates in the coating reaction and becomes a component of the coating; and it has a profound influence on the properties of the coating. Among the metals commercially chromated are zinc and cadmium electroplates; zinc die castings; hot dipped galvanized steel; aluminium (in almost every conceivable form); 
and sometimes copper and silver alloys. Chromate coatings improve corrosion resistance and appearance of metals and adhesion of organic topcoats. The chemistry involves reaction between the metal surface and an aqueous solution containing chromates and certain activator ions. Activators include sulphates, chlorides, fluorides, phosphates and complex cyanides. The solutions for chromating are acidic. A simplified reaction proceeds along these lines:

- Metal at the interface is dissolved by the acid and enters solution as metal ions.

- There is a local rise in $\mathrm{pH}$ (lowering acid content) in the immediate vicinity of the interface.

- Basis metal ions combine with chromate ions to form a compound that is insoluble at the local (higher) pH. This compound precipitates on the metal surface as an adherent coating. - Reaction by-products enter the main solution.

Coatings formed by the reaction are built up from inside out. Since the coating can only be produced by the interaction of the solution with the metal, solution must diffuse through prior layers of the coating and reaction products must diffuse outward. The outermost layer of visible coating is that which was formed initially. Another implication of forming coatings by chemical reaction is that the solution chemistry is continually changing and has to be carefully balanced so that uniform coating properties can be maintained over the entire working life of a chromating bath [9].

Hot dipped galvanized steel coils are often chromated at the mill to prevent white corrosion products from forming during storage. Or they can be chromated on high speed coil coating lines as a pre-paint treatment, to provide corrosion resistance and excellent paint adhesion. The mill process is intended only for passivation and is an inferior adhesive coat for paint. It is also extremely difficult to remove, so that galvanized steel that is ultimately to be painted should be specified without mill chromate passivation (it should be oiled instead). For mill chromating intended for passivation, generally two types of treatments are employed. One is based on hexavalent chromium with a fluoride activator and the other is based on trivalent chromium with a phosphate activator. Both types chromate coatings do not impart any colour to the galvanized sheet surface and are clear in appearance. The solutions are flooded on the galvanized coil directly as it comes from the galvanizing pot. The chromate solution is dilute ( $1 \mathrm{~g} / \mathrm{litre})$ and is not rinsed, but squeezed off. A thin film remains, it reacts with zinc and the coating is dried in place. Coatings are clear, colourless and intended to provide protection until sheet is fabricated, often under outdoor storage conditions at construction work sites. Paint-base chromate coatings are applied on high speed coil coating lines, these are chromate solutions of moderate concentration (10 g/litre) with complex fluoride activators. New coil coating lines can handle widths of sheet metal up to 1500 mm wide and run at 90 metres per minute. Coil is painted inline by reverse-roll-coat methods and subsequently fabricated into residential siding and architectural building panels.
The operation and control of chromate processing solution is simple and treatment times are relatively short, typically a few seconds, and temperature requirements are moderate, ranging from near room temperature to 55-60 oC. The solutions are aggressive, especially those containing fluorides. Satisfactory acid resistant materials are stainless steel (AISI 316L), polyethylene, polypropylene, PVC and rubber. The usual chemical control of a chromating solution consists of a titration to determine hexavalent chromium, and $\mathrm{pH}$ measurements to regulate acidity. Titration of total acid is sometimes used, but the build up of reaction products makes $\mathrm{pH}$ a more reliable choice. Chromate films should not be dried at elevated temperature, since they rupture and lose protective value. For films on zinc, drying temperature should be below $55 \mathrm{oC}$. All chromates are intended to increase the service life of the finished article and this implies improved corrosion resistance. Accelerated tests have been developed I an attempt to predict service life and to compare various treatments. The most common of these is exposure to 5\% salt fog (ASTM B-117 test procedure) [10].

\section{Development of chromating process as applied to zinc}

Initially the process of metal chromating was applied in 1924 to magnesium. The chromate coatings produced at that time, incidentally on a very small scale, and by the methods then used, were brown or olive in colour. Usually acidic sodium dichromate solutions with or without the addition of certain metal salts were used for the purpose In the period 1924-1936 a number of patents concerning the chromating of magnesium, zinc, cadmium, copper and its alloys were released. The most noteworthy is the process in which the bath containing dichromate and sulphuric acid is used. This process, patented in 1936, is well known as the "Cronak" process. Chromate coatings obtained by this method on zinc and cadmium are slightly opalescent, yellow or brown. A further improvement was the application of solutions containing chromic acid and sulphates followed by rinsing in dilute acid or alkali solutions to obtain a bright surface appearance. During second world war, a process was developed enabling the formation of olivegreen chromate coatings on zinc and cadmium. These coatings showed higher corrosion resistance as compared to the slightly opalescent to brown coatings produced previously. A still further improvement was the application of electrolytic treatment of zinc in the chromating solution. Many of the older zinc and cadmium chromating processes recommended the use of dichromate and sulphuric acid solutions are still in current use with some modifications [11].

\section{Mechanism of formation of chromate coatings}

The chromate coatings are produced from chromic acid or chromate solutions containing other additives, most frequently inorganic or organic acids, exerting an activating action. The course of chromate coating formation involves oxidation of the metal surface in the chromating solution with simultaneous transition of the basis metal ions to the solution and evolution of hydrogen. The liberated hydrogen reduces a certain amount of hexavalent chromium to the trivalent state. 
Dissolution of the metal substrate produces an increase of $\mathrm{pH}$ at the metal solution interface up to a value at which trivalent chromium precipitates in the form of gelatinous chromium hydroxide. Certain amounts of hexavalent chromium from the solution and the compounds formed by the chromated metal ions are occluded in this gel.

As mentioned, to initiate the chromating process and to obtain chromate coatings of specific properties organic or inorganic additives are included in the chromating solution apart from hexavalent chromium compounds. The most frequently used additives include sulphuric acid, chlorides, fluorides, nitrates, acetates and formats. The colour and thickness of chromate coatings vary with the conditions of chromating such as composition, $\mathrm{pH}$ and temperature of the bath and time of treatment [12].

The decisive factor for the formation of chromate coatings is the $\mathrm{pH}$ of the chromating solution. The formation of chromate coating is preceded by the dissolution of the substrate metal in conjunction with surface activation. The metals ions produced take part in the reaction. The $\mathrm{pH}$ range most suitable for zinc from this point of view can be seen from Figugre 2. The $\mathrm{pH}$ range of importance for zinc chromating processes lies between 1 and 4; it may be noticed that the dissolution of zinc in this $\mathrm{pH}$ range is significant. The lower the $\mathrm{pH}$ the stronger a zinc substrate is attacked and the higher the probability that the solution will also exert brightening action. The rate of coating formation is the highest at lower $\mathrm{pH}$ values and decreases gradually with increasing $\mathrm{pH}$ [13].

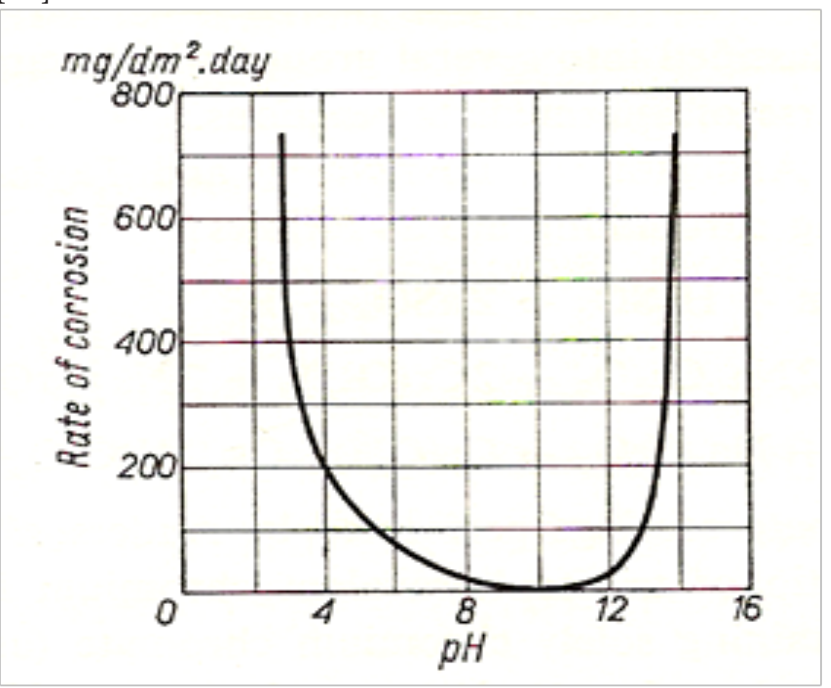

Figure 2: Influence of $\mathrm{pH}$ on corrosion of zinc

The reactions occurring during chromating are as follows:

$\mathrm{Zn}+\mathrm{H}_{2} \mathrm{SO}_{4}=\mathrm{ZnSO}_{4}+\mathrm{H}_{2}$

$3 \mathrm{H}_{2}+\mathrm{Na}_{2} \mathrm{Cr}_{2} \mathrm{O}_{7}=2 \mathrm{Cr}(\mathrm{OH})_{3}+2 \mathrm{Na}_{2} \mathrm{CrO}_{4}$

$2 \mathrm{Cr}(\mathrm{OH})_{3}+\mathrm{Na}_{2} \mathrm{CrO}_{4}=\mathrm{Cr}(\mathrm{OH})_{3} \cdot \mathrm{Cr}(\mathrm{OH}) \mathrm{CrO}_{4}+2 \mathrm{NaOH}[10]$

The compound in Eq.[3] is termed "chromium chromate" which primarily constitutes a chromate coating film. Other reactions include:

$$
\begin{aligned}
& \mathrm{ZnSO}_{4}+\mathrm{Na}_{2} \mathrm{CrO}_{4}=\mathrm{ZnCrO}_{4}+\mathrm{Na}_{2} \mathrm{SO}_{4} \\
& 2 \mathrm{Cr}(\mathrm{OH})_{3}+3 \mathrm{H}_{2} \mathrm{SO}_{4}=\mathrm{Cr}_{2}\left(\mathrm{SO}_{4}\right)_{3}+6 \mathrm{H}_{2} \mathrm{O}
\end{aligned}
$$

The presence of zinc in chromate coatings is attributable to Eq.[11], whereas the formation of trivalent chromium ions and the presence of zinc in the solution is explained by Eqs. [12] and [8] respectively.

The chemistry of chromating process can also depicted by the following set of reactions:

$$
\mathrm{Zn}+2 \mathrm{H}^{+}=\mathrm{Zn}^{2+}+2 \mathrm{H}
$$

As a result of hydrogen recombination reduction may occur according to the following equation:

$$
\mathrm{Cr}_{2} \mathrm{O}_{7}{ }^{2-}+14 \mathrm{H}^{+}+6 \mathrm{e}^{-}=2 \mathrm{Cr}^{3+}+7 \mathrm{H}_{2} \mathrm{O}
$$

For higher $\mathrm{pH}$ values the following reactions are also possible:

$$
\begin{aligned}
& \mathrm{Cr}_{2} \mathrm{O}_{7}^{2-}+\mathrm{H}_{2} \mathrm{O}=2 \mathrm{CrO}_{4}^{2-}+2 \mathrm{H}^{+} \\
& \mathrm{Cr}^{3+}+3 \mathrm{OH}^{-}=\mathrm{Cr}(\mathrm{OH})_{3}
\end{aligned}
$$

In this case, the following reactions would take part in the formation of the chromate coating:

$$
\mathrm{Zn}^{2+}+\mathrm{CrO}_{4}^{2-}=\mathrm{ZnCrO}_{4}
$$

$2 \mathrm{Cr}(\mathrm{OH})_{3}+\mathrm{H}_{2} \mathrm{CrO}_{4}=\mathrm{Cr}(\mathrm{OH})_{3} \cdot \mathrm{Cr}(\mathrm{OH}) \mathrm{CrO}_{4}+2 \mathrm{H}_{2} \mathrm{O}[18]$

Still another set of reactions describing the process are as given below:

$$
\begin{aligned}
& \mathrm{Zn}+2 \mathrm{H}^{+}=\mathrm{Zn}^{2+}+\mathrm{H}_{2} \\
& \mathrm{HCr}_{2} \mathrm{O}_{7}+\mathrm{OH}^{-}=2 \mathrm{CrO}_{4}^{2-}+2 \mathrm{H}^{+} \\
& 3 \mathrm{H}_{2}+\mathrm{HCr}_{2} \mathrm{O}_{7}=2 \mathrm{Cr}(\mathrm{OH})_{3}+\mathrm{OH}^{-}
\end{aligned}
$$

$2 \mathrm{Cr}(\mathrm{OH})_{3}+\mathrm{CrO}_{4}^{2-}+2 \mathrm{H}^{+}=\mathrm{Cr}(\mathrm{OH})_{3} \cdot \mathrm{Cr}(\mathrm{OH}) \mathrm{CrO}_{4}+\mathrm{H}_{2} \mathrm{O}$ [22] It is also believed that the end product may also contain $\mathrm{Cr} 2 \mathrm{O} 3$. In such case, the following reactions are also possible.

$$
\mathrm{Cr}_{2} \mathrm{O}_{7}^{2-}+8 \mathrm{H}^{+}+6 \mathrm{e}^{-}=\mathrm{Cr}_{2} \mathrm{O}_{3}+4 \mathrm{H}_{2} \mathrm{O}
$$

$2 \mathrm{Zn}+6 \mathrm{H}^{+}+2 \mathrm{Cr}_{2} \mathrm{O}_{7}^{2-}+2 \mathrm{e}^{-}=2 \mathrm{ZnCrO}_{4}+\mathrm{Cr}_{2} \mathrm{O}_{3}+3 \mathrm{H}_{2} \mathrm{O}[24]$

In general, coatings formed from dichromate solutions have been found to be 4 to 5 times thicker than those obtained from the equivalent chromate solutions. Because of the absorptive nature of such coatings and the fact that $\mathrm{Cr} 2 \mathrm{O} 72$ is strongly bound to the metal surface, a proportion of $\mathrm{Cr}+6$ is retained even after rinsing and drying; this quantity is related to the chromium concentration in the processing solution.

As seen from the above described mechanisms of chromate coating formation, the reactions and products are essentially the same but the course of intermediate reactions is different for each mechanism. These differences arise out of differences in solution composition and its acidity, which influence the course of reactions.

To increase the acidity of the chromating solutions, it is recommended to use nitric acid, not because of its oxidizing properties but because of the undesirable effects exerted by the other commonly-used acids. Complex cyanide com- 
pounds, for example ferrocyanides, or selenium compounds can also be used as accelerators of chromating processes. Addition of these compounds to chromating baths allows a marked reduction in the time of treatment or bath temperature required to obtain coatings of a given thickness.

\section{Mechanism of corrosion protection by means of chro- mate coatings}

There are two reasons for the protective activity shown by chromate coatings. The first consists in the tightness of these coatings, ensuring an advanced degree of isolation of the metal surface from the corrosive environment. Secondly, hexavalent chromium compounds, which are partly soluble, show well known inhibiting properties at areas of bare metal corresponding to discontinuity sites. Investigations have shown that chromates prevent the formation of white corrosion products on zinc surfaces so long as at least a minimum amount of hexavalent chromium is present in the coating. The time of effective protection by chromate coatings depends on the rate at which hexavalent chromium is washed or leached out from the coating, i.e. on the wettability of the metal surface coated. The degree of corrosion protection attained through chromating, as determined in a study, is given in Table-1 [14].

The effectiveness of protection depends on the amount of hexavalent chromium which is released. This amount varies usually from 0.00001 to $0.005 \mathrm{~g} /$ litre of water in direct contact with the chromate coating. This explanation of the protective role of chromate coatings is supported by the fact that when a chromate coating is scratched resulting in exposure of the underlying zinc surface, the basis metal is still protected against corrosion owing to the evolution of chromates from the surface around the damaged site. It is a common practice to scratch chromate coatings and subject the scribed coating surface to corrosion testing in a salt fog to adjudge the protective value of these coatings. The corrosion protection afforded by scratched hexavalent chromium containing chromate films is often referred to as its "self healing property". This is illustrated schematically in Figure.3.

\begin{tabular}{|l|l|l|l|}
\hline \multirow{2}{*}{ Surface } & \multicolumn{3}{|l|}{ Number of 24 hours' cycles } \\
\cline { 2 - 4 } & $\begin{array}{l}\text { to appear- } \\
\text { ance of zinc } \\
\text { corrosion } \\
\text { products }\end{array}$ & $\begin{array}{l}\text { to appearance } \\
\text { of steel corro- } \\
\text { sion products }\end{array}$ & $\begin{array}{l}\text { to penetra- } \\
\text { tion }\end{array}$ \\
\hline $\begin{array}{l}\text { Unchro- } \\
\text { mated zinc } \\
\text { coating }\end{array}$ & 1 & 90 & 588 \\
\hline $\begin{array}{l}\text { Chromated } \\
\text { zinc coating }\end{array}$ & 38 & 998 & 1768 \\
\hline
\end{tabular}

Table-1: Corrosion of unchromated and chromated zinc coatings on steel in distilled water at ambient temperatures

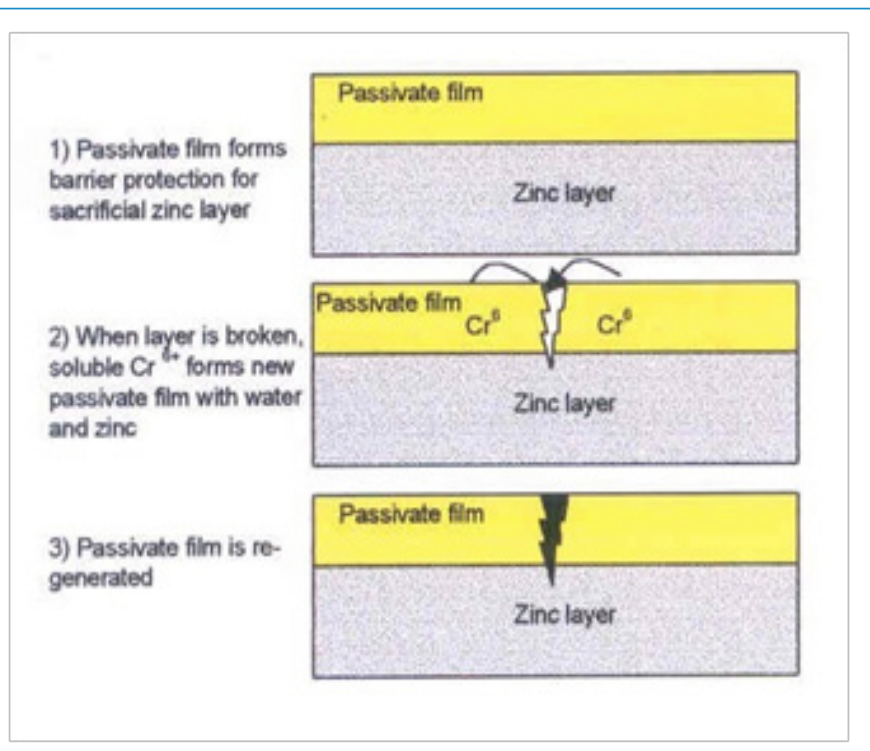

Figure.3 Self healing effect of hevavalent chromium in chromate coatings

The coatings are also expected to contain small but definite amounts of chromates or insoluble hexavalent chromium compounds which also exert very good protective properties. When soluble hexavalent chromium compounds are completely leached, the remaining insoluble part of the coating preserves its initial protective properties [15].

Heating of chromate coatings up to $200 \mathrm{oC}$ and above results in the transition of soluble chromates into insoluble form. A certain decrease in corrosion resistance in the water environment is then observed. The decrease in resistance to corrosion in water may be explained by dehydration and cracking of the coating. The phenomenon of thermallyinduced microcracking in hexavalent chromate coatings is revealed in the scanning electron micrographs (taken at 10000X magnification) given in Figure.4. However, trivalent-based chromate coatings are not susceptible to this kind of thermal microcracking (Figure.4). The micrographs also clearly reveal microcracks in even hexavalent chromium based-passivation films which have not been exposed to any thermal treatment. However, such microcracks do not present a problem in such films as the chromate can regenerate itself due to the presence of soluble hexavalent chromium compounds. Therefore, as long as water and soluble hexavalent chromium remain in the film, film regeneration is possible and the self healing property as well as the protective value is retained. However, heating at temperatures above $60 \mathrm{oC}$ subjects the film to dehydration and the cracks can also become very large as evident from the micrographs and the films lose their protective value. 
(1) Hexavalent before thermal shock

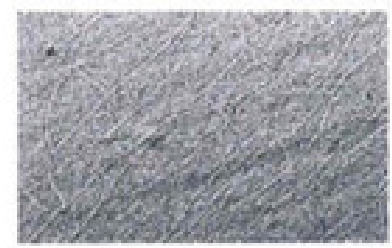

(2) Hexavalent after thermal shock

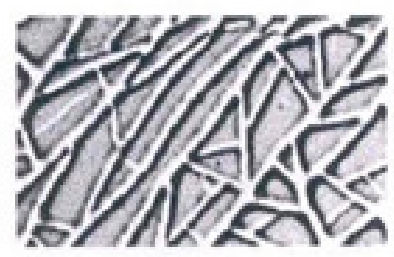

(3) Irivalent before thermal shock

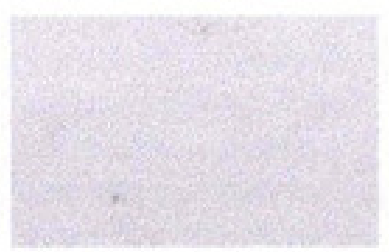

(4) Trivalent after thermal shock
Figure.4 Effect of thermal shock on hexavalent and trivalent chromium films (SEM micrographs at 10000X)

\section{Properties of chromate coatings}

The composition of chromate coatings has not been precisely determined as it has been found to depend to a great degree on the bath composition and parameters of the process. However, it is generally accepted that the main constituents of chromate coatings are tri- and hexavalent chromium compounds and chromates of the basis metal. The following formulae are most frequently ascribed to the chemical compounds occurring in chromate coatings.

$$
\mathrm{Cr}_{2} \mathrm{O}_{3} \cdot \mathrm{CrO}_{3} \cdot \mathrm{xH}_{2} \mathrm{O}
$$

or $\mathrm{Cr}(\mathrm{OH})_{3} \cdot \mathrm{Cr}(\mathrm{OH}) \mathrm{CrO}_{4}$

With zinc as the basis metal, $\mathrm{ZnCrO} 4$ is also observed in the coatings. The most frequently encountered trivalent to hexavalent chromium ratio in the coatings is $28: 8$, other constituents appearing trace amounts only. The typical results of a chemical analysis of chromate coatings on zinc deposited from a solution containing $200 \mathrm{~g} /$ litre sodium dichromate and $6.6 \mathrm{ml} /$ litre sulphuric acid are as given under [16]:

$\begin{array}{ll}\text { Hexavalent chromium } & 7-12 \% \\ \text { Trivalent chromium } & 25-30 \% \\ \text { Total chromium } & 32-42 \% \\ \text { Sulphate } & 2.0-3.5 \% \\ \text { Zinc } & 2.0-2.5 \% \\ \text { Sodium } & 0.2-0.5 \% \\ \text { Water } & 15-20 \%\end{array}$

The composition of the coating is also found to be largely related to its colour. Chromate coatings consist of hydrated complexes of tri- and hexavalent chromium. Trivalent chromium complexes constitute the insoluble part of the coating, impart hardness to it and affect its corrosion resistance. The typical yellow coatings produced from the solution of dichromate and sulphuric acid contain tri- and hexavalent chromium in the form of basic chromic chromate or chromium hydroxide and soluble chromates. Colourless chromate coatings consist mainly of trivalent chromium compounds with no hexavalent chromium content, whereas yellow and green coatings contain large amounts of hexavalent chromium. It is very important to note that the majority of chromate coatings are amorphous and gelatinous when just formed and while still wet, they are soft and exhibit absorptive properties. On drying, they contract and harden and become hardly wettable and resistant to water solutions. Hardening of the coating continues for a certain time after drying, but at a much lower rate.

The colour of the chromate coatings in zinc may vary from transparent colourless and slightly opalescent through yellow, golden yellow, pale green, green, olive, and dark green to brown and even black. The coating colour depends on the nature of the basis metal, its surface roughness, bath composition (trivalent to hexavalent chromium ratio), temperature and $\mathrm{pH}$, activating substances, operation parameters (treatment time, methods of rinsing and drying) and possibly additional treatments (bleaching and sealing with oils). The thickness of chromate coatings can also be roughly estimated from their colour. The thickness of the chromate coatings has been reported variously as ranging from $0.15-1 \mu \mathrm{m}$. The coating thickness is found to increase from transparent and yellow coatings to olive green coatings to bright chromate films. The average chromate coating weights on zinc, cadmium, magnesium and aluminium are given along with coating colours in Figure.5.

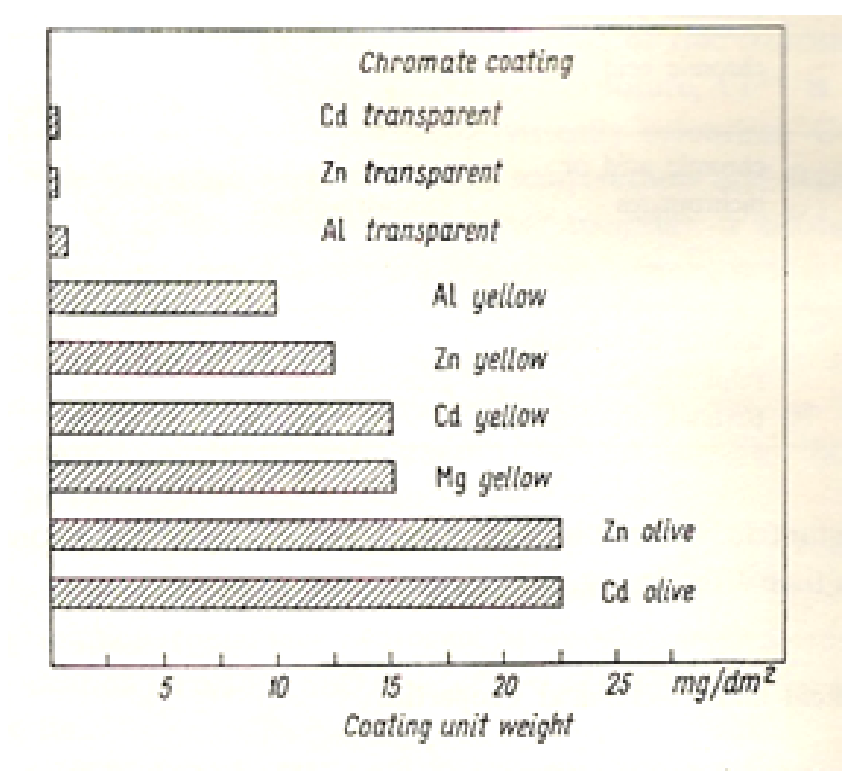

Figure 5: Weights and colours of chromate coatings on $\mathrm{Zn}, \mathrm{Cd}$, $\mathrm{Mg}$ and $\mathrm{Al}$

Chromate coatings are partially soluble in cold water and considerably more soluble in hot water. The solubility decreases as the coating loses water and as oxidation proceeds. The solubility reaches an optimum for most purposes after at least two days ageing under warm-dry conditions. Excessive dessication by over-exposure to high temperatures leads to total insolubilization, and film cracking. The brightness chromate coatings is related to the brightness of the basis metal surface and to an extent, on the polishing action exerted by the 
chromating bath [17].

Before drying chromate coating are porous and may absorb or retain dyestuffs, so that their colour may be modified. Thin films, colourless films and films produced on coarse surfaces tend to be more porous, while thicker coating and coatings produced on smooth and bright surfaces are less porous. Passivating solutions containing suspended particles produce very porous deposits to the extent that corrosion resistance is impaired. Some studies have established that transparent coatings on zinc are highly porous while yellow and olive coatings are almost free from pores. The hardness of chromate coatings depends on the conditions of their formation. Studies have revealed that higher the temperature of the chromating bath, the greater is the hardness of the coating produced. However, application of higher bath temperatures to produce harder coatings results in higher operating costs and in more intensive and destructive action of the vapours emitted from hot chromating solutions. Low abrasion and wear resistance is a serious drawback of chromate coatings. Abrasion resistance is particularly low in thick yellow or olive coatings and especially, in moist coatings but may be increased on drying. The property should be taken into account while handling the coated products during the intermittent period after chromating and before drying. Generally, thinner chromate coatings are more abrasion resistant in the moist condition than the thicker ones.

Adhesion of a chromate coating to the basis metal surface is generally very good because the coating has been formed by a reaction at the metal/solution interface and consists of compounds involving both the basis metal and solution constituents. Chromate coatings are sufficiently ductile to withstand pressing and forming operations and although abrasion will occur, a degree of corrosion resistance will be obtained as the underlying zinc is repassivated by soluble chromium from adjoining areas. The properties of chromate coatings which make them suitable for use as substrates for paint and organic coating application are [18]:

- Chromate coatings enhance paint adhesion because the coating is bonded to the basis metal surface by intermolecular attraction forces and the organic coating adheres well to the relatively smooth chromated surface.

- The low thickness and porosity of chromate coatings results in extremely small absorption of lacquers or other organic materials. This gives certain economical advantages over crystalline paint bases.

- Chromate coatings inhibit corrosion of the basis metal and thus prolong the durability of an organic coating. The chromate coating protects the basis metal against aggressive substances that may penetrate through pores in the organic coating.

- Chromate coatings prevent undesirable reactions between the constituents of the paint coating and the substrate metal.

Because of their gelatinous and amorphous character, chromate coatings neither affect the appearance nor texture nor they cause mechanical contamination or chalking of the ap- plied paint coating. Before painting, the hydrophobic chromated galvanized sheets can be stored for a long time without any hazard of absorption of water vapour that could result in cracking or flaking-off of applied paint coatings.

The effect of elevated temperatures on the properties of chromate coatings is of importance as this may occur in certain operations such as rinsing in hot water, drying, etc. Studies have revealed that heating the chromate coatings at and above $100 \mathrm{oC}$ decreases their corrosion resistance. This reduction is attributable to a continued decrease in hexavalent chromium content. Investigations have also shown that the content of water soluble chromium compounds decreases as the temperature of heating of the chromate coating is increased; the relationship between the amount of leachable chromium compounds and the temperature of heating for various metals is given in Figure.6. Decrease in the corrosion resistance of chromate coatings is associated with dehydration, film cracking and conversion of soluble into insoluble chromium compounds. Figure.7 shows the effect of rinsing water temperature on the corrosion resistance of chromate coatings. The figure shows that rinsing of freshly produced chromate coatings in hot water above 40 oC results in dissolution and thus, in reduced thickness and degraded protective properties of the coatings.

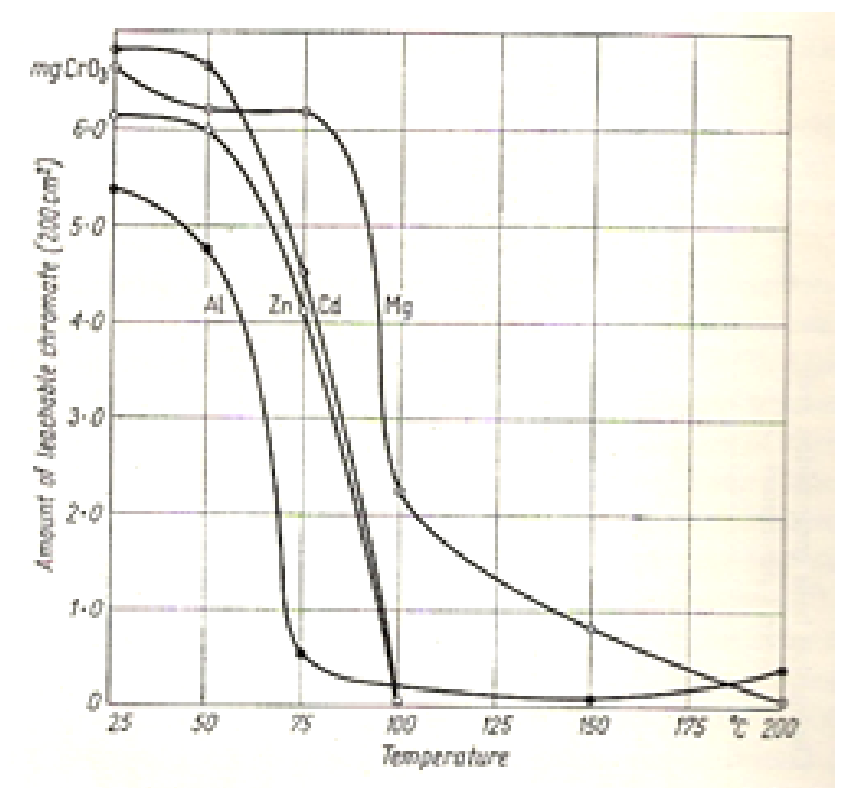

Figure.6 Relation between the amount of leachable chromium compounds and the temperature of heating for chromate coatings produced on various metals 


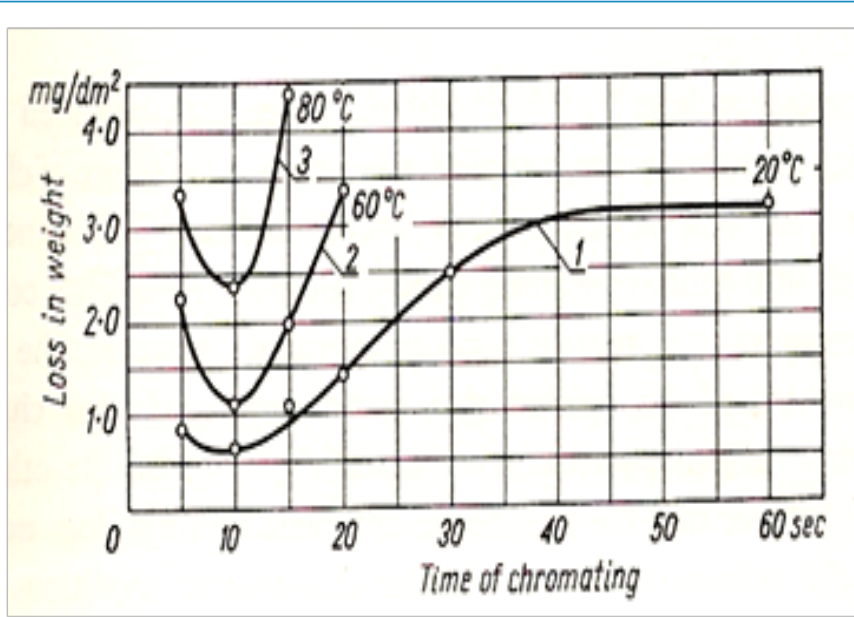

Figure 7: Effect of rinsing water temperature on the corrosion resistance of chromate coatings

\section{Effect of chromating variables on properties}

The chromating bath composition and operating variables have a major influence on the properties of the chromate coatings. The most important factor include sulphate ion concentration, chromating solution acidity, trivalent chromium concentration and bath temperature.

\section{- Effect of basis metal}

Chromate film formation on zinc and its characteristics depends on the impurities co-deposited with zinc on steel. The result is usually difficult to predict in the case of galvanized surfaces due to wide variations in spelter composition, cooling rates, spangles, etc.

\section{- Effect of $\mathrm{pH}$}

One of the more important factors in controlling the formation of the chromate film is the $\mathrm{pH}$ of the treatment solution. For any given metal/ chromate solution system there will exist a $\mathrm{pH}$ at which the rate of coating formation is maximum. As the $\mathrm{pH}$ is lowered from this point, the reaction products become increasingly more soluble, tending to remain in solution rather than deposit as a coating on the metal surface. Even though the rate of metal dissolution increases, the coating thickness will remain low. Increasing the $\mathrm{pH}$ beyond the maximum will gradually lower the rate of metal dissolution and coating formation to the point at which the reaction, for all practical purposes ceases.

\section{- Effect of hexavalent chromium concentration}

While the presence of hexavalent chromium is essential, its concentration in many treatment solutions can vary widely with limited effect compared to that of $\mathrm{pH}$.

\section{- The role of activators}

Chromate films normally will not form without the presence of certain anions in regulated amounts. They are commonly referred to as activators and include acetate, formate, sulphate, chloride, fluoride, nitrate, phosphate and sulphamate ions. The character, rate of formation and properties of the chromate film vary with the particular activator and its concentration. Other important factors which govern the film formation are treatment time, solution temperature, solution agitation, rinsing and drying. Also, solution contamination and solution control are very important.

- The combined effect of sulphate and hydrogen ion concentrations

As the sulphate content is raised at a fixed $\mathrm{pH}$, both the chromate coating weight and the amount of dissolved zinc increase in a chromating bath. Like wise, the weight of the chromate coating on zinc, and thus its thickness, increases as the chromating solution acidity is raised at a constant sulphate ion concentration. The specific properties of activating the growth of chromate coatings on zinc are characteristic not only of sulphates but also of chlorides. An interesting phenomenon is observed when sulphate content and solution acidity are simultaneously increased. The coating weight increases to a maximum and then decreases. The weight of the resulting chromate coating and the amount of the dissolving basis metal in a sodium dichromate solution (200 g/litre) are plotted against the concentration of sulphuric acid (for a treatment time of 30 seconds) in Figure.8. Figure. 9 shows the variation in coating weight and the thickness of basis metal dissolved as a function of $\mathrm{pH}$ of the chromating solution. Figure. 10 shows the effect of time of immersion on the chromate coating weight for different sulphuric acid concentrations [18].

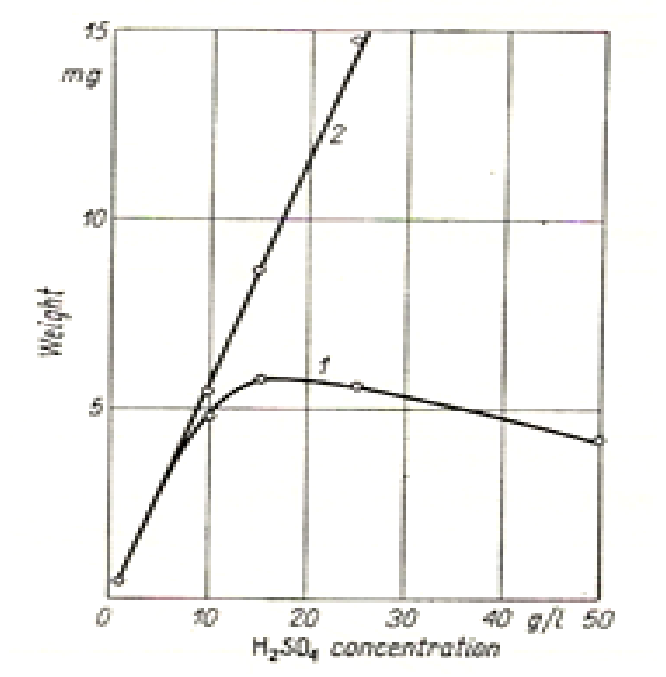

Figure. 8 Weight of chromate coating (1) and dissolved metal (2) with $\mathrm{H} 2 \mathrm{SO} 4$ concentration in chromating bath

The formation of a chromate coating is associated with the dissolution of zinc and simultaneous reduction of hexavalent chromium compounds to trivalent ones. During the course of these reactions, the acidity of the solution near the surface of the basis metal decreases to such a degree that deposition of sparingly soluble hexa- and trivalent chromium compounds which form the chromate coating becomes possible. The rate of metal dissolution rises in the presence of sulphate ions and acids. Like wise, the solubility of trivalent chromium compounds also increases, which favours the formation of chromate coatings of higher thicknesses. 


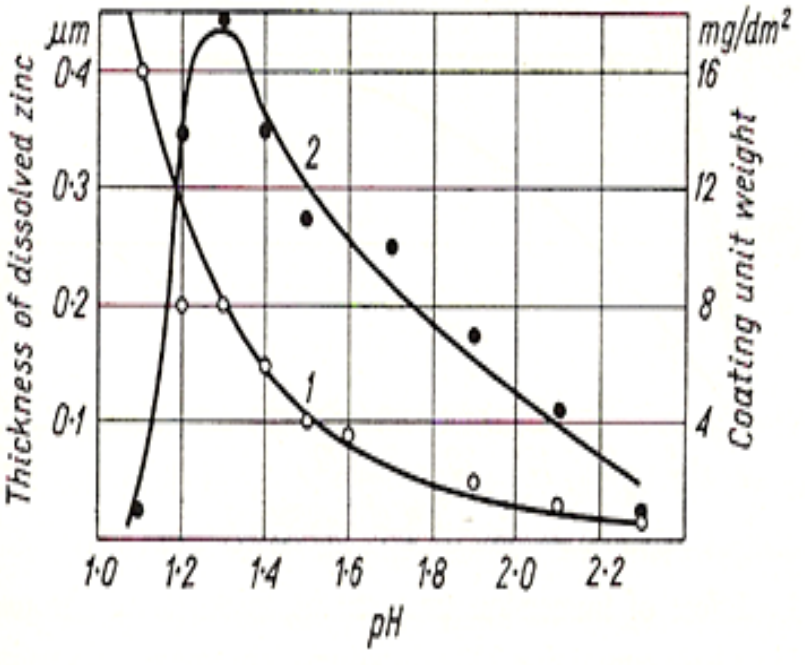

Figure.9 Thickness of dissolved zinc (1) and chromate coating weight (2) on zinc with $\mathrm{pH}$ of the chromating solution

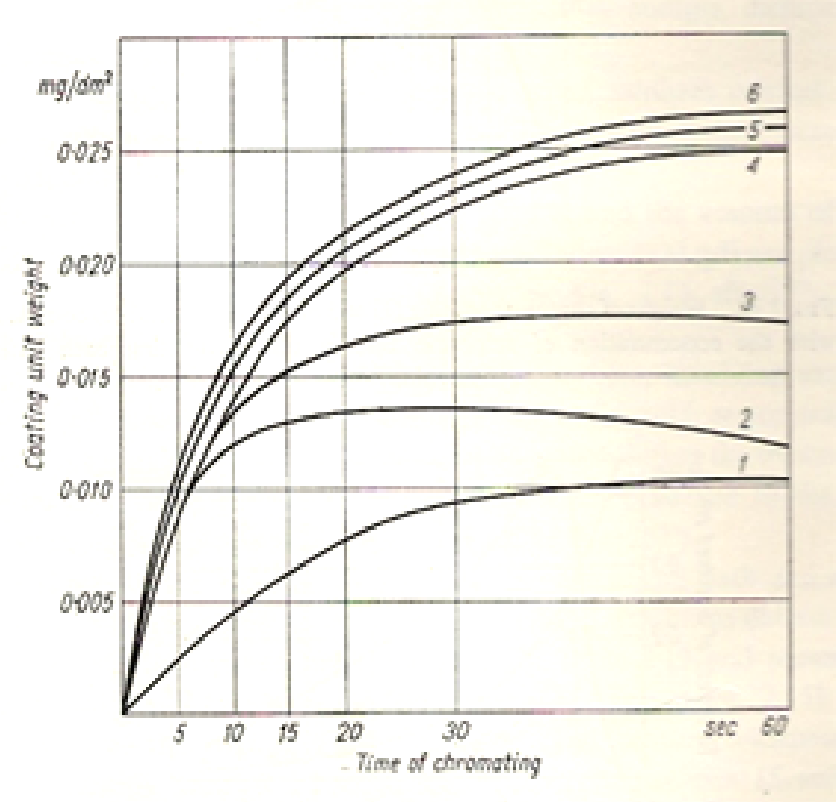

Figure.10 Effect of immersion time on thickness of chromate coating with varying amounts of sulphuric acid

\section{- Effect of trivalent chromium content}

Studies have revealed that at a constant acidity of the chromating solution and identical concentration of sulphate ions, the thickness of chromate coatings is higher when the solution contains trivalent chromium as an additive. The higher the content of trivalent chromium (at constant sulphate concentration), the higher the weight of the chromate coating produced and the higher the rate of metal dissolution. This is attributable to the increase in the acidity (or decrease in the $\mathrm{pH}$ ) of the chromating solution as a result of formation of chromium chromate and liberation of sulphuric acid according to the reaction [19]:

$\mathrm{Na}_{2} \mathrm{Cr}_{2} \mathrm{O}_{7}+\mathrm{Cr}_{2}\left(\mathrm{SO}_{4}\right)_{3}+3 \mathrm{H}_{2} \mathrm{O}=\mathrm{Na}_{2} \mathrm{Cr}_{2} \mathrm{O}_{4}+\mathrm{Cr}_{2} \mathrm{O}_{3} \cdot \mathrm{CrO}_{3}+$ $3 \mathrm{H}_{2} \mathrm{SO}_{4}$

[25]
As mentioned previously, the acidity of the chromating solution near the metal surface decreases markedly in the course of formation of chromate coating. While this increase in $\mathrm{pH}$ is the condition for formation of protective coating, but this rise in $\mathrm{pH}$ also inhibits the further dissolution of basis metal and consequently the build up of chromate coating. Thus, a higher buffer capacity of solutions containing trivalent chromium is conducive to the formation of thicker coatings

\section{- Trivalent to hexavalent chromium ratio}

A properly formulated chromating solution should maintain the trivalent and hexavalent chromium contents within reasonable working limits. However, variations in $\mathrm{pH}$ can upset their ratio and so result in an inferior coating which may be water-absorbent or too low in trivalent chromium content to give adequate corrosion protection.

- Effect of hexavalent chromium to sulphate ratio on the colour of chromate coatings

It has been demonstrated that the colour controlling factor during chromating is the ratio of hexavalent chromium to another anion (such as sulphates) in the chromating solution. Suitable selections of the ratio enable the whole range of colours to be obtained from each chromating solution. Transparent and golden yellow coatings may be obtained from solutions of low total concentrations.

\section{- Effect of temperature on formation of chromate coatings}

Figure.11 depicts the thickness build-up of a chromate coating on zinc as a function of the time of immersion for different solution temperatures ranging from $0-30{ }^{\circ} \mathrm{C}$. It is evident from the graphs that when the solution temperature is raised, there is a perceptible increase in the weight of the chromate coating. However, some studies have also revealed that raising the temperature of chromating solution, particularly above 50 ${ }^{\circ} \mathrm{C}$, lowers the thickness of the chromate coating considerably. This is believed to be due to the increased formation of chromate coatings containing unhydrated products of reaction.

\section{- Effect of the movement of the chromated parts}

Figure.12 shows the thickness build up of chromate coatings as a function of time of immersion in chromating solution under static and dynamic conditions of the chromated part. Moving the parts during chromating results in a considerable increase in the coating thickness compared to the coatings produced under static treatment conditions. This is because in agitated solution film formation is more rapid as hydrogen ions are continuously replenished at the zinc surface and this offsets the drop in acidity at the metal/solution interface. 


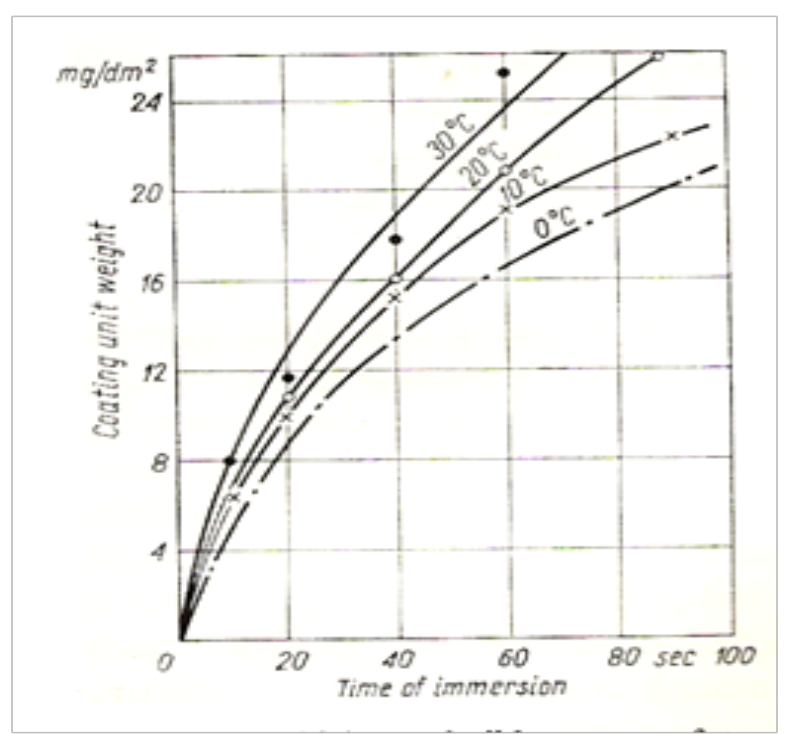

Figure.11 Thickness buildup rate of chromate coating on zinc with solution

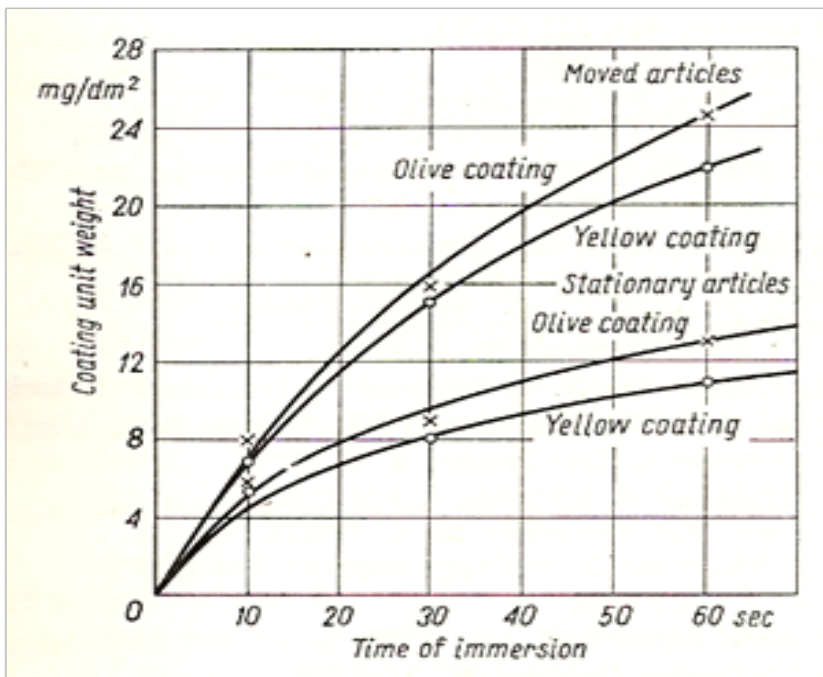

Figure.12 Thickness build-up rate of chromate coating vs. time of immersion tempature for moving and stationary parts at RT

It is pertinent to mention that chromate coatings can be removed by immersing the parts in a hot chromic acid solution ( $200 \mathrm{~g} / \mathrm{litre})$ for a few minutes. Hydrochloric acid may also be used for the same purpose. Before rechromating, however, the articles should be rinsed in an alkaline bath and in water. Some of the typical bath compositions employed for chromating zinc are given in Table- 2 .

\section{Coating evaluation}

\section{- Coating evaluation by visual inspection}

The easiest way to evaluate chromate conversion coatings is to observe the colour, uniformity of appearance, smoothness and adhesion. Type of colour and iridescence is a guide to film thickness, which is considered proportional to protective value. However, visual inspection is not sufficient by itself, to indicate the protective value of the coating, especially if the film has been overheated during drying [20].

\begin{tabular}{|c|c|c|c|}
\hline Bath composition & $\begin{array}{l}\text { Time of im- } \\
\text { mersion, sec }\end{array}$ & \begin{tabular}{|l|} 
Temperature, \\
${ }^{\circ} \mathbf{C}$
\end{tabular} & $\mathrm{pH}$ \\
\hline $\begin{array}{l}\mathrm{CrO}_{3} 30 \mathrm{~g} / \mathrm{l} \\
\mathrm{Na}_{2} \mathrm{Cr}_{2} \mathrm{O}_{7} 220 \mathrm{~g} / 1 \\
\mathrm{H}_{2} \mathrm{SO}_{4}\end{array}$ & $12-20$ & $15-25$ & - \\
\hline $\begin{array}{l}\mathrm{KCr}\left(\mathrm{SO}_{4}\right)_{2} 20 \mathrm{~g} / 1 \\
\mathrm{HNO}_{3} 5 \mathrm{~g} / 1\end{array}$ & $10-40$ & $15-25$ & - \\
\hline $\begin{array}{l}\mathrm{CrO}_{3} 100 \mathrm{~g} / \mathrm{l} \\
\text { (or } \mathrm{Na}_{2} \mathrm{Cr}_{2} \mathrm{O}_{7} \text { ) } \\
\mathrm{NaCl}_{1} \mathrm{~g} / \mathrm{l} \\
\mathrm{H}_{2} \mathrm{SO}_{4} \text { or } \mathrm{NaOH} \\
\text { (to adjust } p \mathrm{H} \text { to } 1.6 \text { ) }\end{array}$ & $10-30$ & $15-25$ & 1.6 \\
\hline $\begin{array}{l}\mathrm{Na}_{2} \mathrm{Cr}_{2} \mathrm{O}_{7} 200 \mathrm{~g} / \mathrm{l} \\
\mathrm{Na}_{2} \mathrm{SO}_{4} 10 \mathrm{~g} / \mathrm{l}\end{array}$ & $120-300$ & $15-25$ & 1.2 \\
\hline $\begin{array}{l}\mathrm{Na}_{2} \mathrm{Cr}_{2} \mathrm{O}_{7} 200 \mathrm{~g} / \mathrm{l} \\
\mathrm{KCr}\left(\mathrm{SO}_{4}\right)_{2} 50 \mathrm{~g} / 1\end{array}$ & $120-300$ & $15-20$ & 2.3 \\
\hline $\begin{array}{l}\mathrm{ZnCr}_{2} \mathrm{O}_{7} 142 \mathrm{~g} / \mathrm{l} \\
\mathrm{H}_{2} \mathrm{SO}_{4} 3 \mathrm{ml} / 1\end{array}$ & 10 & $15-20$ & - \\
\hline $\begin{array}{l}\mathrm{CrO}_{3} 5 \mathrm{~g} / \mathrm{l} \\
\mathrm{Na}_{2} \mathrm{SO}_{4} 15 \mathrm{~g} / 1 \\
\mathrm{HNO}_{3} 2 \mathrm{ml} / 1 \\
\end{array}$ & $30-45$ & $15-20$ & - \\
\hline
\end{tabular}

Table-2 Bath compositions for chromating zinc

\section{- Accelerated corrosion tests}

The salt spray test, based on ASTM-B-117 [10] standard testing procedure, is the most common accelerated test developed in specification form. While some disagreement exists as to the correlation of salt spray tests to actual performance, it remains in many specifications. Variations in results are often obtained when tested in different salt spray cabinets, and even in different locations within the same cabinet. The angle of exposure to the salt fog is also very important and angular variance also causes discrepancies in the results. B-117 states that (unless otherwise specified) test specimens shall be positioned so that the surface is $150-30 \mathrm{o}$ from the vertical. The severity of the test increases with the test angle. Coatings should be aged for at least 24 hours before testing for consistent results. Generally, specifications require a minimum exposure time before visible corrosion forms.

\section{- Humidity tests}

There appears to be no standard specification covering humidity tests for unpainted chromate conversion coatings. Evaluations are conducted under various conditions and cycles. Humidity tests may be more useful than salt spray tests, since they correspond to the normal environment better than the salt spray except in marine atmospheres.

\section{- Water tests}

Immersion tests in distilled or de-ionized water have proved invaluable in simulating such conditions as water accumulation on chromated galvanized sheets and coils. Coatings 
applied on hot dipped galvanized surfaces in strip mills are often tested by stacking wet sheets and weighing the top sheet. Periodic checks are made to determine when corrosion products first develop. The tests should be conducted at relatively constant temperatures to insure consistent results.

\section{- Chemical and spot tests}

The amount of hexavalent chromium in the film can be an indication of corrosion protection afforded by the coating. Analytical procedures for small amounts of chromium on treated surfaces are comparatively rapid, quantitative and reproducible. Consequently, chemical analysis for the chromium content of the film appears to be a valuable tool. It would not be suitable, however, for predicting the performance of bleached, overheated, excessively dehydrated coatings. Total coating weight is sometimes used as an indication of corrosion resistance. It is derived by weighing a part having a known surface area before and after chemically stripping only the chromate film.

Spot tests are used to test corrosion resistance by dissolving the chromate coating and reacting with the basis metal. The time required to produce a characteristic spot determines empirically the film thickness or degree of corrosion protection. It is advisable to use these tests as comparative tests only, always spotting an untreated and treated surface at the same time. Frequently, the spot tests are sufficient only to indicate differences between treated and untreated surfaces. Reproducibility is not good since aging affects the results.

\section{- Performance tests for organic finishes}

Paint, lacquer and other organic finishes on the chromate conversion coatings are tested in numerous ways to evaluate bonding and corrosion protection. These include pencil hardness, cross-hatch, bending, impact and tape tests with or without prior exposure to water or salt spray.

\section{Performance evaluation of chromic acid based passi- vators- RDCIS experience}

The comparative performance of two proprietary chromic acid based passivators under 5\% salt fog test gives an insight into the effect of treatment parameters and the role of hexavalent chromium concentration in the white rust initiation on hot dip galvanized sheets. Figures.13-17 show the rusting pattern; the effect of solution concentration, treatment temperature and time on white rust initiation; and the variation in hexavalent chromium content with the solution concentration for both passivators. The results can be interpreted in the light of foregoing discussions.

\section{Conversion Phosphating Mechanism}

The principle of phosphating is that the surface of a metal part becomes coated with a metal phosphate layer after immersion in a dilute phosphoric acid solution. The formation of a protective layer consists of electrochemical conversion of this surface in solutions containing primary heavy metal phosphates into an electrically insulating phosphate coating. The metal to be phosphated is immersed in an aqueous solution of a primary phosphate $\mathrm{Me}++(\mathrm{H} 2 \neg \mathrm{PO} 4) 2$ containing a certain amount of free phosphoric acid ( $\mathrm{Me}++$ stands for $\mathrm{Fe}++, \mathrm{Zn}++$ or $\mathrm{Mn++}$ ). In such a solution at the metal/solution interface the chemical equilibrium of the dissolved salt moves towards the formation of secondary and tertiary salts insoluble in this medium [21]:

$$
\begin{aligned}
& \mathrm{Me}\left(\mathrm{H}_{2} \mathrm{PO}_{4}\right)_{2}=\mathrm{MeHPO}_{4}+\mathrm{H}_{3} \mathrm{PO}_{4} \\
& 3 \mathrm{Me}\left(\mathrm{H}_{2} \mathrm{PO}_{4}\right)_{2}=\mathrm{Me}_{3}\left(\mathrm{PO}_{4}\right)_{2}+4 \mathrm{H}_{3} \mathrm{PO}_{4}
\end{aligned}
$$

or, in terms of an overall ionic reaction:

$$
4 \mathrm{Me}^{2+}+3 \mathrm{H}_{3} \mathrm{PO}_{4}=\mathrm{MeHPO}_{4}+\mathrm{Me}_{2}\left(\mathrm{PO}_{4}\right)_{2}+5 \mathrm{H}^{+}[28]
$$

The concentrations of $\mathrm{Me} 2+, \mathrm{H}+, \mathrm{H} 2 \mathrm{PO} 4-$ and HPO42- ions in phosphating solution should be adjusted in such a way that even a small suppression of the hydrogen ion concentration should give rise to the displacement of the chemical equilibrium of Eq.[28] at the operating temperature towards the formation of insoluble phosphates. Hydrogen ions are neutralized on dissolution of zinc in the phosphoric acid.

$$
\mathrm{Zn}+2 \mathrm{H}^{+}=\mathrm{Zn}^{2+}+\mathrm{H}_{2}
$$

associated with simultaneous evolution of hydrogen. The resulting insoluble phosphates deposit out on the metal surface and adhere to it well as they have formed at the very reaction sites. Simultaneously, a direct reaction between the basis metal and primary phosphates may take place:

$$
\begin{aligned}
\mathrm{Zn}+\mathrm{Me}\left(\mathrm{H}_{2} \mathrm{PO}_{4}\right)_{2} & =\mathrm{MeHPO}_{4}+\mathrm{ZnHPO}_{4}+\mathrm{H}_{2}[30] \\
\mathrm{Zn} & \text { or, } \quad \mathrm{Me}\left(\mathrm{H}_{2} \mathrm{PO}_{4}\right)_{2}=\mathrm{MeZn}\left(\mathrm{HPO}_{4}\right)_{2}+\mathrm{H}_{2}
\end{aligned}
$$

Primary divalent iron, zinc and manganese phosphates are readily soluble, whereas secondary/ tertiary phosphates are insoluble in water, except for sparingly soluble zinc phosphate. Precipitation of these phosphates at the metal surface results in the formation of a coating insoluble in the medium. The state of equilibrium in the bulk of the solution is not disturbed as the reaction sites are restricted to the metal surface and the phosphoric acid formed during the course of the reactions practically compensates for the loss of the acid consumed in the reaction. Consequently, the hydrogen ion concentration in the bulk of the solution vary only slightly.

Apart from the total to free phosphoric acid ratio, bath concentration is an important factor in phosphating. Extreme dilution of the bath results in decrease in phosphoric acid concentration and thus in precipitation of phosphates in the bulk of the solution. On the other hand, in over concentrated baths, precipitation of insoluble phosphates occurs very slowly or may totally stop.

Phosphating is believed to be a topochemical reaction of electrochemical nature in which the corrosive dissolution of metal takes place at microanodes whereas the discharge of hy- 


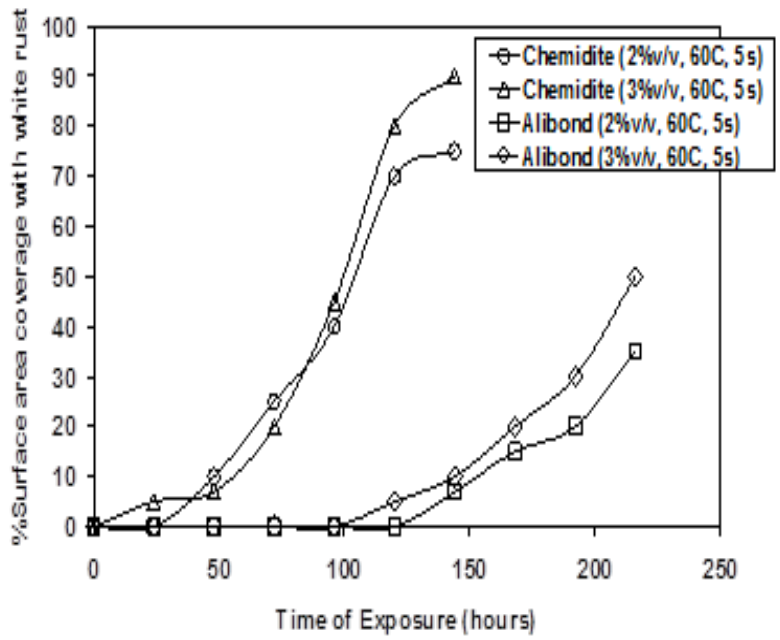

Figure.13 Rusting pattern of galvanized sheet under different proprietary chromic acid passivation treatments (5\% Salt fog test).

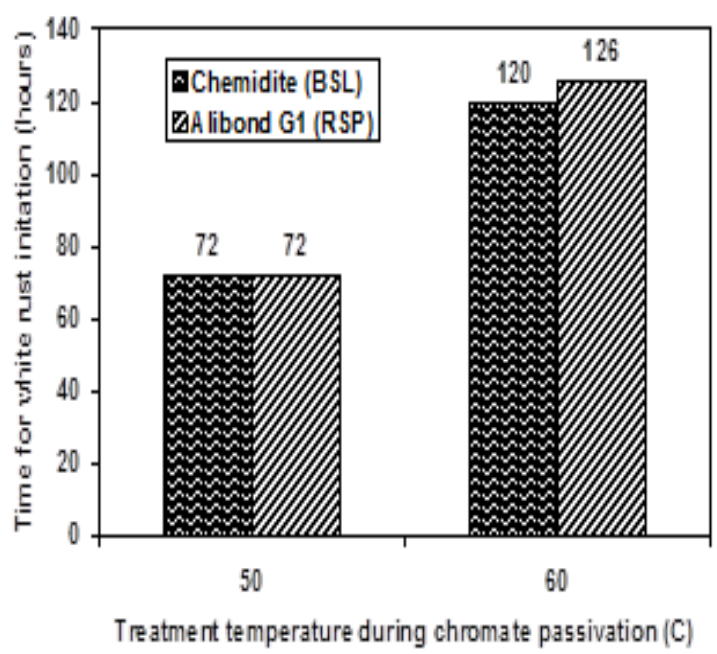

Figure.15 White rust initiation as a function of treatment temperature during chromate passivation (Passivator conc.$1 \% \mathrm{v} / \mathrm{v}$; treatment time- $20 \mathrm{~s}$ ).

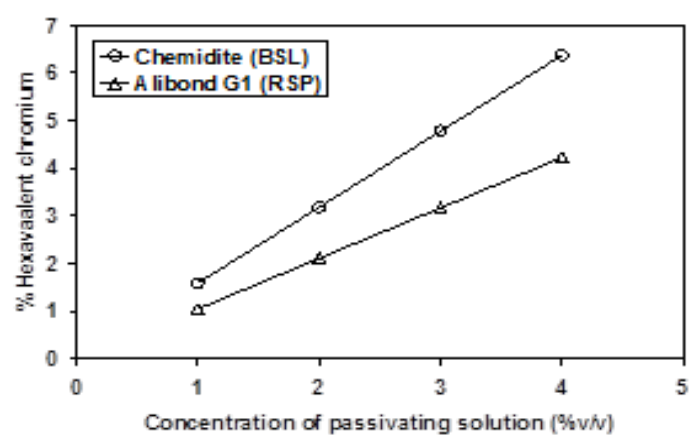

Figure.17\% Hexavalent chromium as a function of concentration of passivating solution

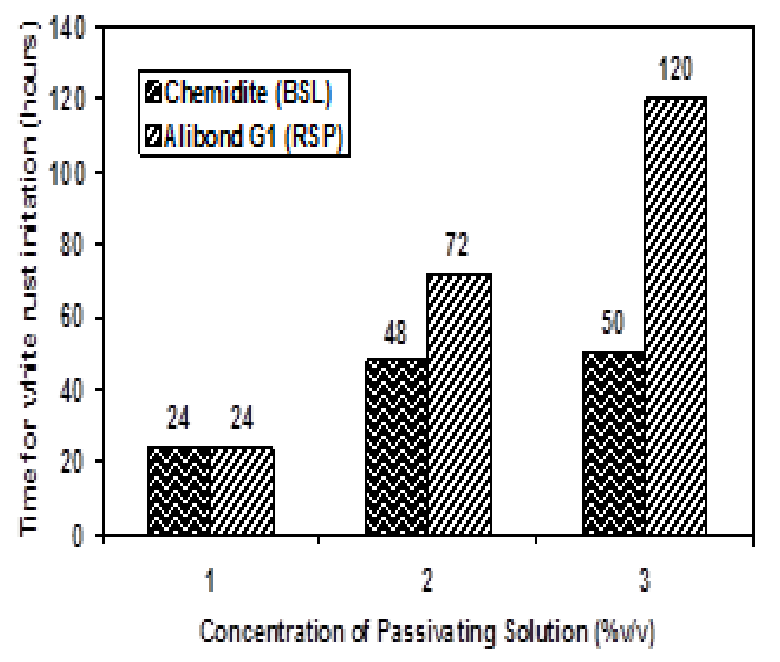

Figure.14 White rust initiation in galvanized steel sheet as a function of passivator concentration (Treatment temp.$50 \mathrm{oC}$; treatment time- $5 \mathrm{~s}$ )

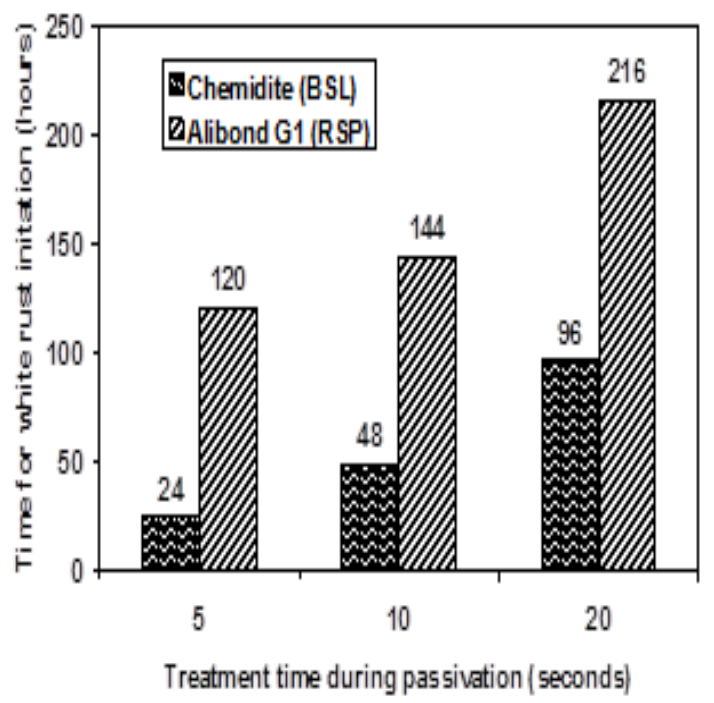

Figure.16 White rust initiation as a function of treatment time during chromate passivation (Passivator conc.- $3 \% \mathrm{v} / \mathrm{v}$; treatment temperature- $60 \mathrm{oC}$ ). 
drogen ions, followed by hydrolysis and precipitation of insoluble phosphates, takes place at microcathodes. The formation of a phosphate coating, i.e. precipitation of tertiary metal phosphates, is caused by the rise in the $\mathrm{Me}^{+}$cation concentration due to the basis metal dissolution reaction and the rise in $\mathrm{pH}$ at cathodic sites. This results the solubility product of phosphates being exceeded and leads to the deposition of the coating [22].

Ordinary phosphating baths (for slow treatment) contain a primary zinc, manganese or ferrous phosphate with the addition of phosphoric acid in an amount suitable for the given treatment. Precipitation of secondary or tertiary phosphates takes place within certain $\mathrm{pH}$ limits, which are specific to the main cation in the solution and depends on the concentration of this cation and H2PO4- ion. As the concentration of hydrogen ions is decreased, the phosphates will precipitate in the following order: $\mathrm{Fe}^{3+}, \mathrm{Zn}^{2+}, \mathrm{Mn}^{2+}$, and $\mathrm{Fe}^{2+}$. Baths involving zinc phosphate will contain more phosphoric acid (and thus exhibit lower $\mathrm{pH}$ ) than manganese or ferrous phosphate based solution. In zinc phosphate solutions, the coating is formed more rapidly than in manganese or ferrous phosphate solutions. Zinc phosphate baths also enable alloy steels to be phosphated which are very difficult to treat in manganese phosphate solutions. With progressive usage, sludge consisting of insoluble phosphates builds up in the bath owing to the more and more basis metal dissolution which after attaining a certain concentration starts to precipitate in the form of secondary and tertiary phosphates in the bath. Also, as the treatment goes on, the bath becomes impoverished in manganese or zinc and increasing more secondary or tertiary ferrous phosphates are deposited in the coating [23].

The formation of a phosphate coating can be chemically, mechanically or electrically accelerated. In addition to the primary zinc or manganese phosphate and phosphoric acid, chemically accelerated phosphating baths contain special additions which promote the rapid formation of coatings at low temperature of treatment (40-80 oC depending on bath composition). Mostly, these are oxidizing compounds, for e.g. nitrites, nitrates or chlorates. The accelerating action of the oxidizers consists in oxidizing the hydrogen formed on dissolution of metal by phosphoric acid; additionally, the accelerators oxidize divalent iron ions in the solution according to the reaction:

$2 \mathrm{Fe}+2 \mathrm{Fe}\left(\mathrm{H}_{2} \mathrm{PO}_{4}\right)_{2}+4 \mathrm{O}=4 \mathrm{FePO}_{4}+4 \mathrm{H}_{2} \mathrm{O}$

The resulting insoluble ferric phosphate precipitates in the form of sludge. Zinc content in the accelerated solutions, after an initial decrease, is maintained at a constant level during the entire period of bath usage and the volume of sludge produced from such baths is markedly low. Modern phosphating baths usually contain several types of accelerators and various modifiers like calcium compounds, organic acids, borates, fluorides, etc. The electrochemical acceleration of the phosphating process is achieved by cathodic treatment during the course of phosphating. The coatings obtained by electrophosphating are very thin and finely crystalline. The mechanical acceleration of phosphating is achieved by spraying of solutions containing chemical accelerators. This eliminates the delay due to diffusion and the coatings produced are thin and finely crystalline. The accelerating influence of above methods is believed to be due to cathodic polarization.

\section{Properties of phosphate coatings}

The phosphate coatings produced on zinc and zinccoated steel show a crystalline structure with crystals varying from a few to about $100 \mu \mathrm{m}$ in size. Usually, the larger the crystals the thicker the coating. Depending on the kind of phosphating solution, temperature and time of treatment, mthod of surface preparation, etc., the coating thickness varies within the limits of 1 to $20 \mu \mathrm{m}$. The phosphate coating consists of the crystals of secondary and tertiary phosphates of such metals as zinc, manganese and iron. The zinc phosphate coating consists mainly of hopeite $\left[\mathrm{Zn}_{3}\left(\mathrm{PO}_{4}\right)_{2} \cdot 4 \mathrm{H}_{2} \mathrm{O}\right]$ and phosphophyllite $\left[\mathrm{Zn}_{2} \mathrm{Fe}\left(\mathrm{PO}_{4}\right)_{2} \cdot 4 \mathrm{H}_{2} \mathrm{O}\right]$. The zinc phosphate layers show excellent orientation effects and epitaxial growth with the substrate. Solution containing zinc and calcium phosphates produce on zinc particularly fine crystalline coatings consisting of two phase constituents, hopeite and scholtzite. The phase composition of phosphate coatings produced from different phosphating baths are summarized in Table- 3 and the typical scanning electron micrographs of fine crystalline zinc and manganese phosphate coatings are given in Figure.18. Figure.19 shows the progressive growth of a zinc phosphate coating as viewed under a scanning electron microscope.

\begin{tabular}{|l|l|}
\hline $\begin{array}{l}\text { Main constituents of phos- } \\
\text { phating bath }\end{array}$ & Phase composition on zinc \\
\hline Zinc phosphate & $\mathrm{Zn}_{3}\left(\mathrm{PO}_{4}\right)_{2} \cdot 4 \mathrm{H}_{2} \mathrm{O}$ (Hopeite) \\
\hline $\begin{array}{l}\text { Zinc phosphate/ calcium } \\
\text { phosphate }\end{array}$ & $\begin{array}{l}\mathrm{Zn}_{3}\left(\mathrm{PO}_{4}\right)_{2} \cdot 4 \mathrm{H}_{2} \mathrm{O} \text { (Hopeite) } \\
\mathrm{Zn}_{2} \mathrm{Ca}\left(\mathrm{PO}_{4}\right)_{2} \cdot 7 \mathrm{H}_{2} \mathrm{O} \\
(\mathrm{Scholtzite})\end{array}$ \\
\hline Manganese phosphate & $\begin{array}{l}\mathrm{Zn}_{3}\left(\mathrm{PO}_{4}\right)_{2} \cdot 4 \mathrm{H}_{2} \mathrm{O} \text { (Hopeite) } \\
\mathrm{Mn}_{5} \mathrm{H}_{2}\left(\mathrm{PO}_{4}\right)_{4} \cdot 4 \mathrm{H}_{2} \mathrm{O} \text { (Hure- } \\
\text { alite) }\end{array}$ \\
\hline
\end{tabular}

Table-3 Phase composition of phosphate coatings

Owing to the porosity and structure, phosphate coatings can adsorb oil, grease, soap, etc. This adsorption enhances the corrosion resistance and permits the application of phosphate coatings for cold forming of galvanized sheets; in this case the phosphate coating together with the oil or soap adsorbed plays the role of a lubricant. The phosphate coatings also improve paint adhesion, thereby increasing the corrosion resistance of the paint system. Without additional after treatment (sealing), phosphate coatings cannot afford sufficient corrosion protection to the treated metal. Sufficient protection may be obtained after the application of an oil, paint or lacquer coating. The porosity of all coatings, irrespective of the method of phosphating, obtained from solutions of conventional composition is equal to about $0.5 \%$. The highest corro- 
sion resistance is shown by the manganese phosphate coatings produced by hot phosphating.

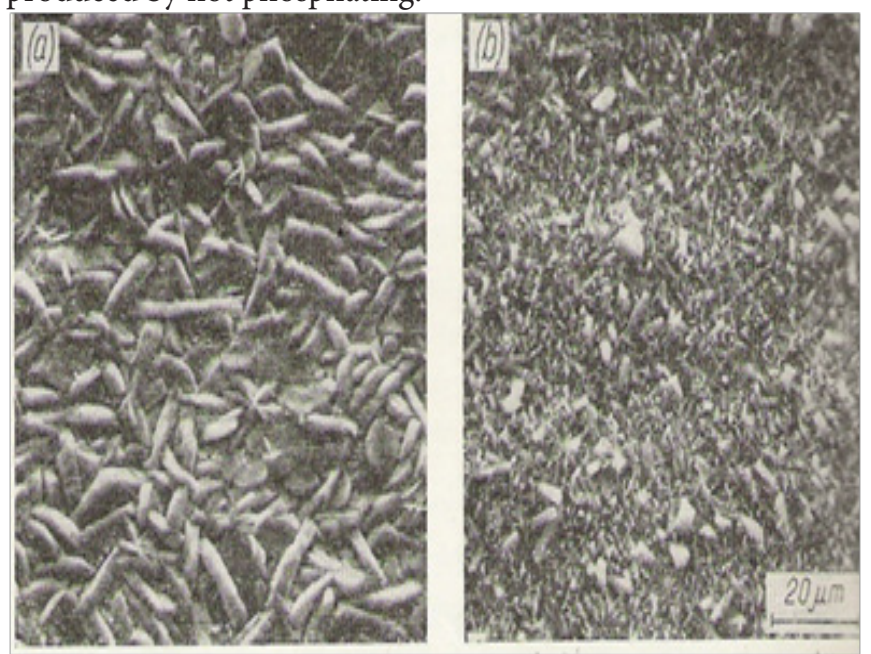

Figure 18. Fine crystalline phosphate coatings [a] Zinc phosphate [b] Manganese phosphate

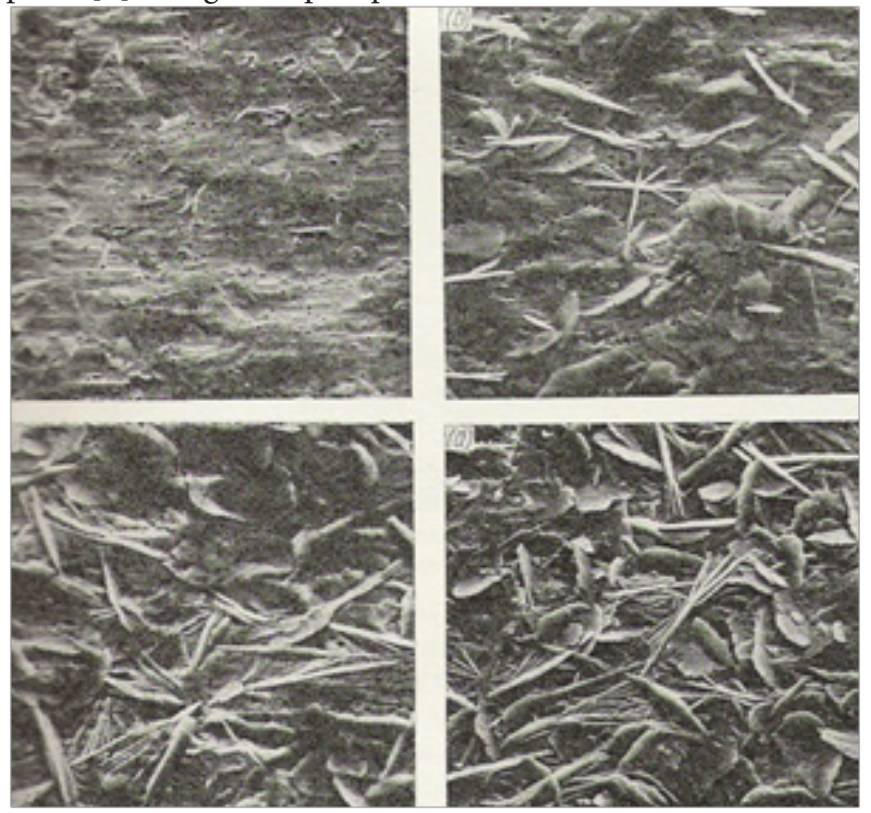

Figure.19 Growth of zinc phosphate coating (under SEM; gold replica) [a] after $3 \mathrm{~s}$ treatment, [b] $10 \mathrm{~s}$, [c] $30 \mathrm{~s}$, [d] $60 \mathrm{~s}$.

The factors that influence the properties of phosphate coatings are:

\section{- Surface preparation of phosphated metal}

Among the factors that influence the coating properties, surface preparation of the phosphated metal has a pronounced effect on the course of phosphating and on the coating properties such as fineness of crystals, uniformity, oil and paint absorption. In general, the following methods of surface preparation are advantageous:

- Mechanical rubbing, wiping, grinding, sand blasting.

- Emulsion degreasing, kerosene wiping.

- Activating cleaned metal surface in dilute solutions of salts of nobler metals, oxalic acid, titanium phosphate, etc.

The detrimental influences are degreasing in strongly alkaline solutions, pickling in strong mineral acids and physical defects on the metal surface.

\section{- Influence of phosphating parameters}

The quality of the phosphate coating also depends on the concentration, composition and temperature of the phosphating solution. The hydrogen ion concentration has a considerable influence on the coating formation reaction:

$$
3 \mathrm{Me}^{2+}+2 \mathrm{H}_{2} \mathrm{PO}_{4}^{-}=\mathrm{Me}_{3}\left(\mathrm{PO}_{4}\right)_{2}+4 \mathrm{H}^{+}
$$

as is evident from the formula determining the equilibrium constant of phosphate precipitation:

$$
\mathrm{K}=\frac{\left[\mathrm{H}^{ \pm}\right]^{4}}{\left[\mathrm{Me}^{2+}\right]^{3}\left[\mathrm{H}_{2} \mathrm{PO}_{4}^{-}\right]^{2}}
$$

A smaller but important influence in the above reaction is played by the concentration of heavy metal ions $(\mathrm{Zn}$, $\mathrm{Mn}, \mathrm{Fe}$ ) and $\mathrm{H} 2 \mathrm{PO} 4-$ ions. For these reasons a constant ratio should be maintained between the contents of free and total phosphoric acid. This ratio is defined as the acid coefficient and is determined by titration methods. Depending on the kind and composition of the solution, this coefficient varies within the limits of 4 and 9. Usually, higher the coefficient, the more fine grained are the coatings produced. The acid coefficient depends closely on the $\mathrm{pH}$ value of the phosphating bath [24].

The total bath concentration must also be kept within strictly specified limits. Too low concentrations result in the formation of coatings of poor corrosion resistance. Decreasing the concentration of heavy metal ( $\mathrm{Zn}, \mathrm{Mn})$ ions in the accelerated phosphating solution too reduces the protective value of the coatings. The concentration of an accelerator must be sufficiently high but too much may cause passivation of the metal surface which makes it difficult for the growth of well developed coatings. Lowering the bath temperatures below the normal value results not only in prolongation of phosphating but also in decreasing the protective properties of the coatings. At low temperatures, good coatings may be obtained only when sufficiently strong accelerators are applied, for instance spray phosphating or nitrite accelerated solutions. Specific additions to phosphating baths are small amounts of polyphosphates (such as sodium tripolyphosphate). They promote a reduction in the thickness of the phosphate coating with a simultaneous decrease in porosity. The lower the thickness of phosphate coating the higher is the resistance of the applied paint coating to mechanical deformation.

The free pore area of the phosphate coating can be reduced by after-treatment in dilute (about $0.01 \%$ ) solutions of chromic acid or its salts. This increases the corrosion resistance of the coating itself and improves the behaviour of applied paint coatings, particularly under humid conditions. The best sealing (passivating) properties are shown by a partially reduced $(\mathrm{Cr}+6: \mathrm{Cr}+3=3: 1) \quad 0.015 \%$ chromic acid solution and by the same solution with the addition of phosphoric acid (CrO3:H3PO4 = 5:1). The zinc phosphate coatings 
heated in the absence of air lose their corrosion resistance at temperatures between 150 and $1630 \mathrm{o}$, i.e., at the transition of orthorhombic into the monoclinic form. Also the losses of hydration from zinc, iron and manganese phosphate coatings are dependent on temperature.

For phosphating zinc and its alloys, good results are obtained with slow phosphating solutions containing increased amounts of ferrous phosphate. The iron content in the zinc phosphate bath must be 1.3-1.5 times as high as the zinc content, whereas the iron content in the manganese phosphate bath must be at least twice as high as the manganese content. Very good results are obtained by using solutions operated at room temperature; under these conditions even zinc coated sheet can be satisfactorily phosphated owing to the low bath aggressiveness and zinc is not so rapidly dissolved. A typical solution and parameters for phosphating galvanized steel strip are summarized in Table-4. More difficult to phosphate are the zinc-aluminium alloys. Aluminium dissolving in the solution is an excellent negative catalyst of phosphating and in amounts as low as $0.5 \mathrm{~g} /$ litre may completely prevent the formation of a phosphate coating. Therefore, for these alloys, phosphating is recommended in solutions operated at room temperature which dissolve aluminium very slowly or to add sodium fluoride or sodium fluo-silicate ( $2 \mathrm{~g} /$ litre $)$ which precipitate aluminium from the bath. An alternative method is to selectively dissolve aluminium from the alloy surface in $10 \%$ sodium or potassium hydroxide solution, such that the surface layer consists almost entirely of zinc.

\begin{tabular}{|l|l|l|l|l|}
\hline $\begin{array}{l}\text { Major } \\
\text { compo- } \\
\text { nent }\end{array}$ & $\begin{array}{l}\text { Coating } \\
\text { thickness, } \\
\text { mm }\end{array}$ & $\begin{array}{l}\text { Method } \\
\text { of pro- } \\
\text { cessing }\end{array}$ & $\begin{array}{l}\text { Temperature, } \\
{ }^{\circ} \mathrm{C}\end{array}$ & $\begin{array}{l}\text { Time, } \\
\mathrm{sec}\end{array}$ \\
\hline $\begin{array}{l}\text { Zinc } \\
\text { phos- } \\
\text { phate }\end{array}$ & $2-4$ & $\begin{array}{l}\text { Spray for } \\
\text { continu- } \\
\text { ous phos- } \\
\text { phating of } \\
\text { zinc-coat- } \\
\text { ed steel } \\
\text { strip }\end{array}$ & $50-60$ & $10-30$ \\
\hline
\end{tabular}

Table-4 Typical solution and parameters for phosphating galvanized steel strip

\section{Corrosion Protection using Organofunctional Silanes as Major Constituent in Organic Coatings}

Hexavalent chromium ions have been reported to be toxic and carcinogenic. The need for chromate replacements for surface treatment in many metal finishing industries has prompted an intensive search for replacement technologies in the recent years. Among the replacements that have been proposed, those that are based on the use of organofunctional silanes rank very high in terms of performance, broad applicability and ease of application. Silane films obtained by simple rinses can be formulated by means of additives such as nanoparticles, colourants and inhibitors. With these modifications the silane processes can duplicate or outperform the perfor- mance of chromate conversion coatings in terms of having a colour for detection purposes, being applied from aqueous solution and exhibiting the capability to protect the metal substrate at a scratch (self-healing effect) [25].

Silanes are organofunctional hybrid organic-inorganic compounds used primarily as coupling agents for adhesion between organic and inorganic interfaces. These functional silanes contain hydrolyzable alkoxy groups such as methoxy, ethoxy or acetoxy, and an organofunctional group. The silane structure is $(\mathrm{XO})_{3} \mathrm{Si}\left(\mathrm{CH}_{2}\right)_{\mathrm{n}} \mathrm{Y}$ where $\mathrm{XO}$ is the hydrolyzable group and $\mathrm{Y}$ the organofunctional group. After some degree of hydrolysis in water or water/alcohol mixtures, the silane molecules contain a sufficient number of hydrophilic silanol groups -Si-OH which make the molecules hydrophilic so that they are readily adsorbed when contacted with a clean metal surface. Hydrogen bonds are formed between silanol groups and surface hydroxyls. After adsorption, such bonds slowly convert to metallo-siloxane bonds, as shown in Figure.20.

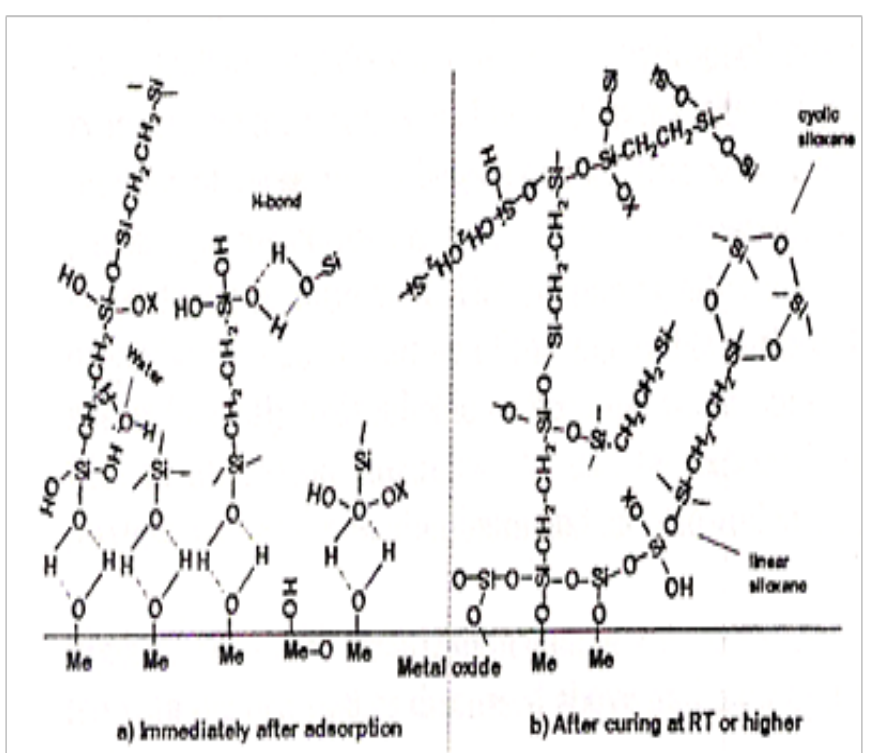

Figure 20. Adsorption of partly hydrolyzed silane on a clean metal surface

This reaction can be speeded up by heating the film to moderate temperatures. Inside the adsorbed film, the silanols react with themselves with the formation of -Si-O-Si(siloxane) bonds. It is important to note that $-\mathrm{Si}-\mathrm{OH}$ group is very hydrophilic (i.e. it adsorbs water by hydrogen bonds) but the siloxane chain -Si-O-Si-O-Si-O-Si- is very hydrophobic, particularly if one of the substituents on the silicon atom is a carbon atom. This phenomenon is called crosslinking and a crossliked silane film such as the one shown in Figure.20 on the right can protect a metal from corrosion due to a slow rate of diffusion of water into the film. Although -Me-O-Si- and -Si-O-Si- bonds can be hydrolyzed again by water, this process is very slow because of their hydrophobic nature. Silane films display outstanding corrosion-inhibiting properties due to this reversal of hydrophobicity to hydrophobicity [26]:

Hydrophilic ester $\longrightarrow$ Hydrophilic silanol $\longrightarrow$ Hydrophobic siloxane 
No other surface treatment has this same propensity. Nevertheless, although the concept looks simple, it also poses a dilemma from application point of view. The silanes that are strongly hydrophobic and, therefore, preferred from a corrosion standpoint, are the same ones which present a problem of hydrolysis for formation of sufficient concentration of silanols for application onto the metal surface. The hydrolysis is slow and sometimes not possible even in solvents like ethanol. Such silanes can only be applied from water/ solvent mixtures with high levels of solvents. Therefore, current research is directed at identifying silane systems which are sufficiently hydrophilic for complete dissolution and hydrolysis in water only, but at the same time form a hydrophobic film after drying and crosslinking.

The silane bis-[trimethoxysilylpropyl] amine ("bisamino") is soluble in water and hydrolyzes readily, but does not protect most metals very well from aqueous corrosion. This is because the secondary amino group is easily protonated making the film hydrophilic and the metal corrodes right through the film, i.e. the film has a poor barrier action. The silane bis-[triethoxysilylpropyl] tetrasulphide ("bis-sulphur") on the other hand is very hydrophobic; it does not dissolve in water and requires about $90 \%$ ethanol for dissolution and hydrolysis. This hydrolysis is incomplete and proceeds very slowly. Films of this silane too do not protect zinc very well because of porosity; the lack of protection attributable to an insufficient wetting of the zinc oxide by the hydrophobic silane. This wetting can be considerably improved by adding small amount of the hydrophilic bis-amino silane. This small amount does not impair the hydrophobicilty very much. The result is a $1: 3 \mathrm{v} / \mathrm{v}$ mixture of these two silanes protects zinc very well against aqueous corrosion, whereas the two individual silanes do not perform well. The mixture is sufficiently hydrophilic for a good wetting of the zinc oxide surface, but still sufficiently hydrophobic to keep the water out of the film in immersion situations. These results prove two points: first, a mixture of these two silanes is more effective than the two individual silanes and secondly, the underlying reason why silanes work so well is only by barrier action. This fact is revealed in Figure. 21 which shows the DC polarization curves of hot dip galvanized sheet samples without any treatment and those treated with the two silanes individually and their optimized 1:3 v/v mixture. The electrochemical data reveals a decrease in the corrosion current with silane treatments but reveals no change in corrosion potential, which indicates that there is no electrochemical corrosion-inhibiting effect associated with silane treatment unlike chromate films. Thus, the better the wettability of the silane, the better is the performance due to more effective adsoption on the metal surface. In the case of bis-sulphur silanes, the wettability is improved by using higher proportion of alcohol solvent in the water/alcohol mixtures. This is revealed in Figure.22, which shows that the film made from the solution that contained lower water content reduced the corrosion current to a greater extent. Again, no change in corrosion potential is observed which implies that the film formed from the solution with the higher alcohol content has the highest barrier action. Further, this film shows a clear pitting potential unlike the other. This means that a film of higher resistance, i.e. a less porous film is formed from high alcohol solution [26-28].

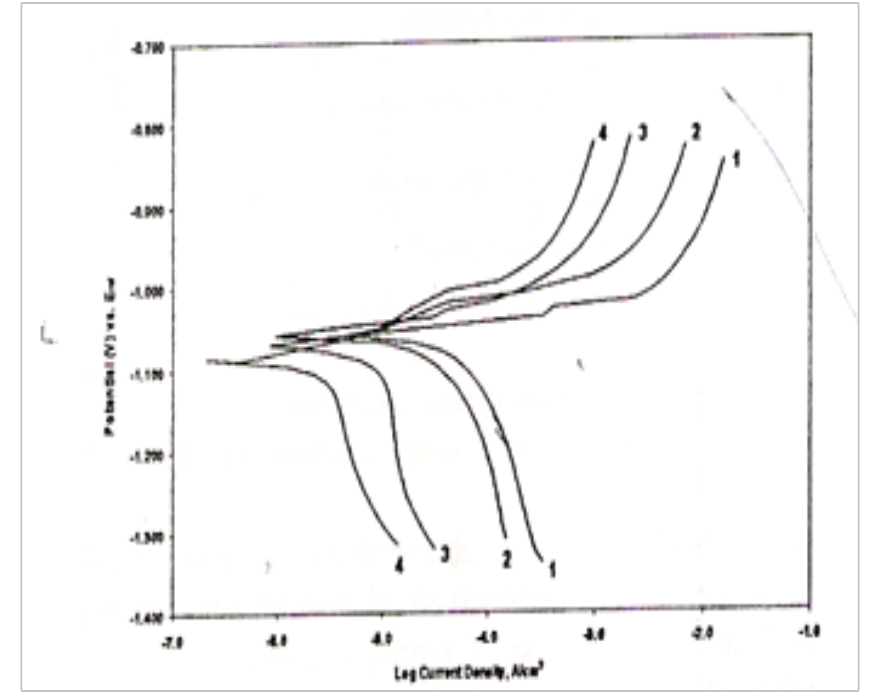

Figure.21 Polarization curves in $3.5 \% \mathrm{NaCl}$ for $\mathrm{HDG}$ panels 1) untreated 2) treated with $5 \%$ bis-amino silane 3 ) treated with $5 \%$ bis-sulphur silane 4 ) treated with $5 \% 1: 3 \mathrm{v} / \mathrm{v}$ ratio of bis-amino and bis-sulphur silanes.

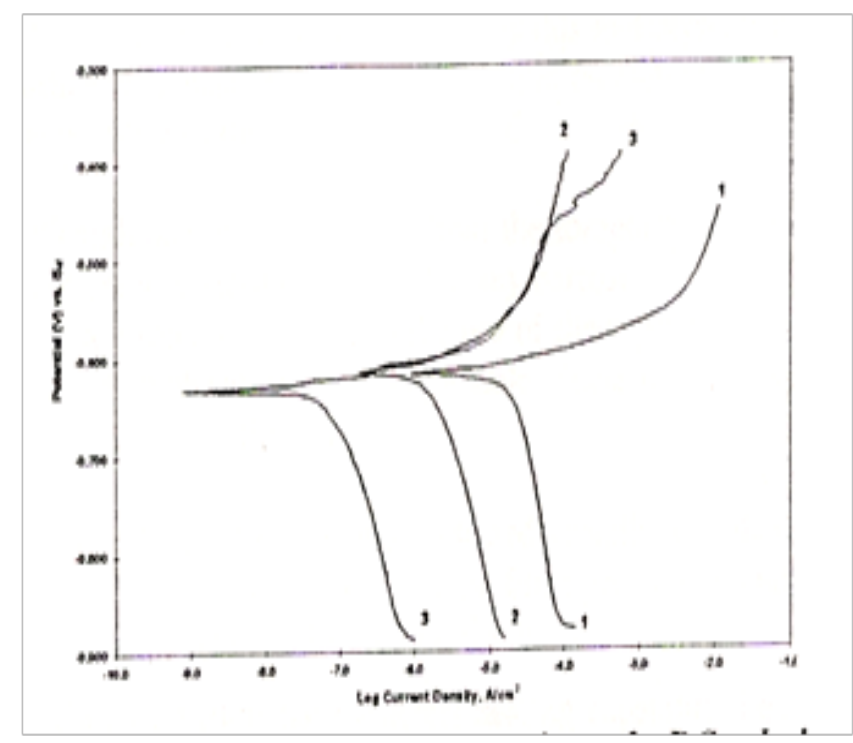

Figure. 22 Effect of watert/ethanol ratio on polarization curves of test panels treated with bis-sulphur silane 1) untreated 2) treated with $5 \%$ ethanol/water/silane $77 / 18 / 5$ solution 3 ) treated with $5 \%$ ethanol/water/silane $90 / 5 / 5$ solution (in $3.5 \% \mathrm{Na}$ $\mathrm{Cl})$.

Studies have also revealed that the barrier action of bis-amino silane films can be improved by mixing with a vinyltriacetoxysilane (VTAS) (which by itself cannot be used) to yield silane mixtures which are completely hydrolysable in water alone and have a shelf life of well over one year. Films prepared from bis-amino/VTAS system contain vinyl groups and secondary amino groups which enable bonding to paints, epoxies, polyesters and polyurethanes. Figure. 23 shows the comparative polarization curves in $3.5 \% \mathrm{NaCl}$ for the untreated and treated samples (with this silane system). It is seen that there is an order of magnitude reduction in corrosion current 
which is less than the two orders of magnitude reduction obtained with bis-amino/bis-sulphur silane films. The difference is due to higher concentration of secondary amino groups which are hydrophilic. They make the film more permeable to water and electrolyte. The permeability of bis-amino/VTAS system can be reduced by additives such as nanoparticles, water-soluble inhibitors, tetraethoxysilane (TEOS), etc. The effect of some of these additives is discussed subsequently in this paper.

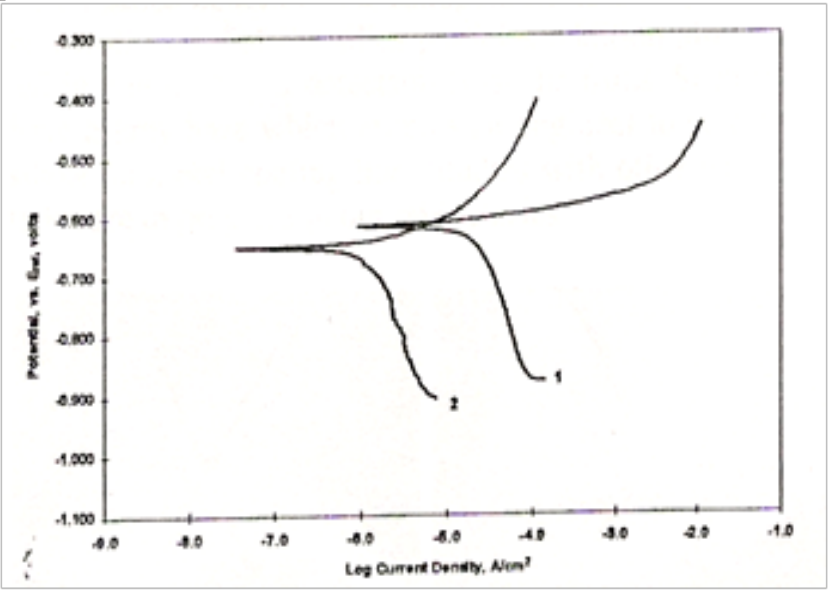

Figure.23 Polarization curves in $3.5 \% \mathrm{NaCl}$ of test panels treated with hydrophilic silane

An interesting observation is that bis-silanes with two $\mathrm{Si}$ atoms in the molecular structure are more protective than the mono-silanes. This is because monosilanes can form only a monolayer of dense -Me-Si-O- bonds; whereas with bis silanes, the film thickness can be extended through the second silicon atom without compromising the density of -Me-O-Siunits at the interface.

Thus for silanes to perform well as corrosion inhibiting films, the following factors are important:

- the wetting of the metal oxide by the silane solution

- the alcohol content of the solution

- the age of the solution

- the solubility of the silane in water

- the hydrophobicity of the silane film after drying and curing

- the curing time and temperature

Remarkably, the degree of hydrolysis of the silane is not a major factor, as long as the hydrolysis is sufficient to make the silane hydrophilic enough to become readily adsorbed on the metal oxide surface. However, the limitations of silanes are:

- Silane films cannot be detected visually.

- Unlike chromate films, silanes do not have a defect healing capability.

- Silane solutions have a limited shelf life, as the hydrolyzed silanol groups will undergo condensation reaction over time which precipitates and renders silane molecules insoluble. The typical shelf life of a hydrolyzed silane solution is a few days.

- Silane films are very thin $(\sim 0.3 \mu \mathrm{m})$ so they cannot provide long term protection other than in painted state.

However, research has shown that certain modifications of the silane films can duplicate or surpass the perfor- mance of chromate films. One way of improving corrosion inhibiting property of silanes is through addition of nanoparticles, such as of silica, to the silane films. Nanoparticles are chosen for surface modification because of the relative thinness of the silane films. It has been found that the impregnated nanoparticles introduce an electrochemical effect; they reduce the corrosion current considerably and at the same time lower the corrosion potential thus acting as cathodic inhibitors. The nanosilica is added in the form of a water suspension to the water/alcohol mixtures used to hydrolyze the silane. The nanoparticles also add to the detectability of the silane films. Such films have a grey haze which enables silane detection in a coil coating line. Another method of enabling detection of the films on continuous coating lines consists of adding colourants or dyes to the silane films. An example is that of hot dip galvanized steel panels treated with silanes containing a red or yellow xanthene dye. These dyes are soluble in water and/or alcohol, but become insoluble after curing of the silane films. Thus, these colourants or dyes are not leached out of the film even under highly humid conditions. The third category of additives to silane films are water-soluble inhibitors such as cerium chloride $(\mathrm{CeCl} 3)$ and tolyltriazole which are slowly leached out from the silane film under conditions of high humidity from the high $\mathrm{pH}$ cathodic sites and protect scratched and abraded areas of the film where zinc is exposed, providing a "self-healing" effect as in the case of chromates. The inhibitors are also found to affect the cathodic oxygen reduction reaction during electrochemical polarization of these silane films. Thus, the films of silanes on metals can be modified extensively by certain additives in order to achieve the unique attributes of chromate films; that of colour and the self healing property [29-30].

\section{Alternative Passivation Technologies for Hot Dip Gal- vanized Sheet}

Conventionally, hexavalent chromium based passivation treatments have been used for improving the corrosion resistance of sacrificial zinc and zinc alloy coatings on ferrous substrates for many years. However, due to restrictions imposed by environmental legislative bodies on the use and disposal of hexavalent chromium and resultant demand for environmental friendly corrosion protection mechanism for hot dip galvanized coatings, alternative hexavalent chromiumfree technologies are being investigated and subjected to a great deal of intensive research by the galvanizers worldwide. The basic requirements for hexavalent chromium-free technologies are two-fold- barrier corrosion protection for the zinc coating and the "self healing" property at the sites of cuts and scratches of passivation coating on a galvanized sheet. Although all the newly investigated technologies depend on barrier layer formation on a zinc coating for corrosion protection, but only few of them incorporate the "self-healing" mechanism. In Figure.24, the different investigated technologies are presented schematically. The studies are split into alternatives for passivation and for thin organic coatings. On one hand, systems have been studied which are hexavalent chromium- 
free but contain trivalent chromium and on the other hand, totally chromium-free systems have been taken into account. For the trivalent chromium passivation, two types of treatments, inorganic and organic constituents based, have been investigated. The totally chromium-free systems can be divided into five main classes- conversion molybdating, tannic acid coating, colloidal silica/ organic silicate based coating layer formation, silane-based organic treatments, electrolytic phosphate coatings, solutions with different metallic ions ( $\mathrm{Zr}$, $\mathrm{Ti}, \mathrm{Mo}, \mathrm{Ce}$ ) as active compounds or the formation of a selfassembled monolayer (SAM) [31-33].

Trivalent chromium coatings are one of the preferred replacements for hexavalent chromium coatings because of less toxicity. As discussed earlier, trivalent chromium passivating films possess better thermal shock resistance and are essentially microcrack free at temperatures of around $150 \mathrm{oC}$, which corresponds to the "underhood" temperatures encountered near the automobile engines. Trivalent chromium films are seen to perform as well as hexavalent chromium films under accelerated corrosion test conditions although the selfhealing effect is not exhibited by them because of their relative insolubility. They also exhibit excellent capabilities of dyestuff adsorption. The chromium-free films include the use of organic acrylic polymers with silane coupling agents, colloidal silica and other additives.
These films offer high corrosion resistance, anti-fingerprinting resistance and anti-chemical resistance [34-36].

Molybdate based formulations have also raised considerable interest due to their low toxicity; the treatments are cathodic in nature and the final coating contains molybdenum in (VI), (V) and (IV) valencies. Solutions are usually formulated using sodium molybdate $(\mathrm{Na} 2 \mathrm{MoO} 4.2 \mathrm{H} 2 \mathrm{O})$ and the $\mathrm{pH}$ is adjusted with additions of concentrated sulphuric acid. Reducing agents such as phenol sulphonic acid and ascorbic acid are frequently used with these solutions to regulate the process.

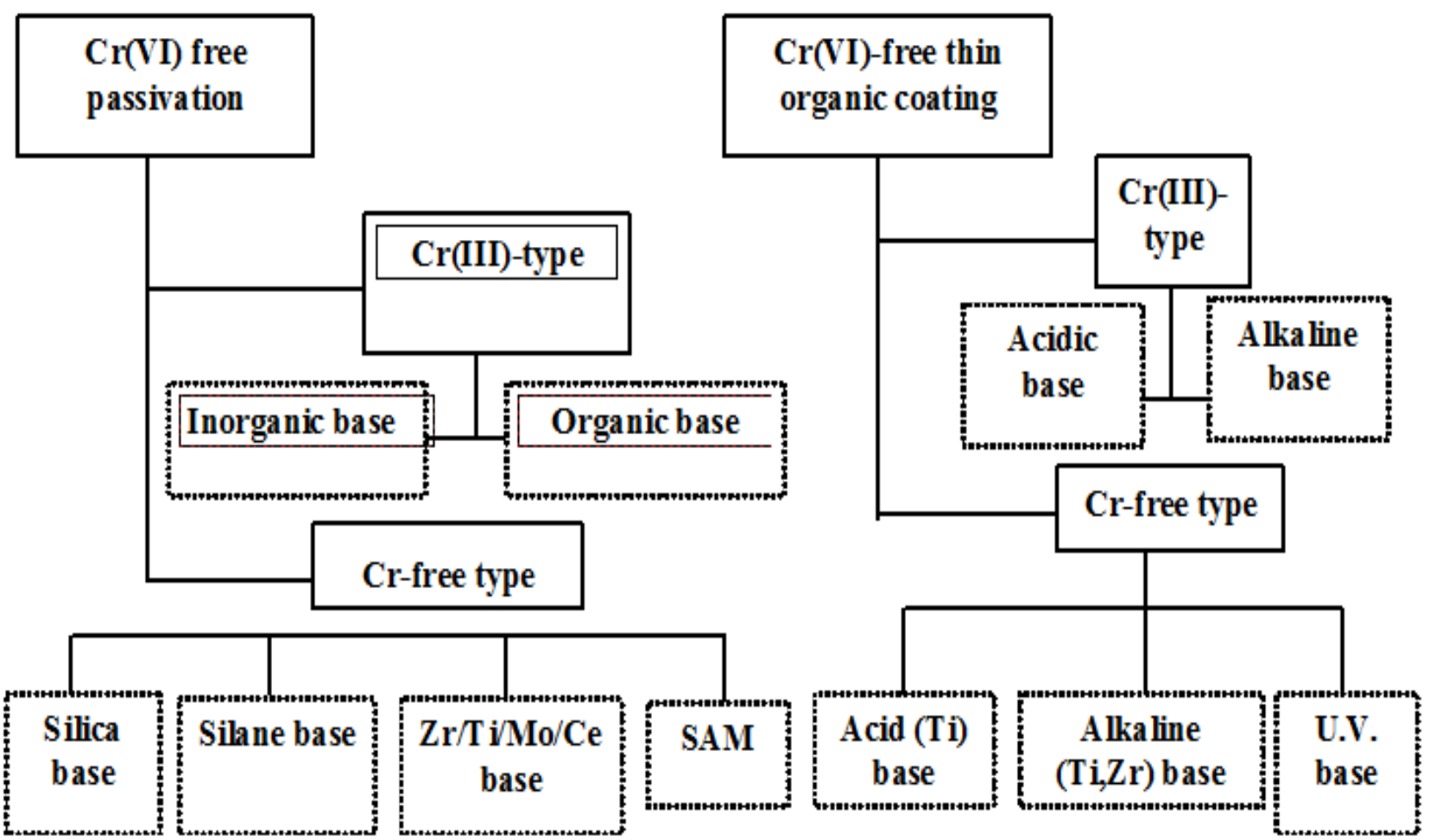

Figure.24 Alternative hexavalent chromium-free passivation/ thin organic coating technologies for hot dip galvanized sheet 


\section{References}

1. T. Prosek, A. Nazarov, H. B. Xue, S. Lamaka, D. Thierry (2016) "Role of steel and zinc coating thickness in cut edge corrosion of coil coated materials in atmospheric weathering conditions; Part 1: Laboratory study", Progress in Organic Coatings 99:356-364.

2. A.J.Stavros "Continuous Hot Dip Coatings", Metals Handbook, American Soc. of Metals 13:432-434.

3. S Feliu, V Barranco (2003) "XPS study of the surface chemistry of conventional hot-dip galvanised pure $\mathrm{Zn}$, galvanneal and $\mathrm{Zn}-\mathrm{Al}$ alloy coatings on steel", Acta Materialia 51: 54135424.

4. Zhiqiang Gao, Dawei Zhang, Xiaogang Li, Sheming Jiang, Qifu Zhang (2018) "Current status, opportunities and challenges in chemical conversion coatings for zinc", Colloids and Surfaces A: Physicochemical and Engineering Aspects 546:221-236.

5. G. Vourlias, N. Pistofidis, D. Chaliampalias, E. Pavlidou, P.Patsalas, et al. (2006)“A comparative study of the structure and the corrosion behavior of zinc coatings deposited with various methods", Surface and Coatings Technology 200:65946600 .

6. Galvatech '04 (2004) 6th Intl. Conf. on Zinc and Zinc Alloy Coated Sheet Steels, Chicago, USA.

7. Thomas Lostak, Artjom Maljusch, Björn Klink, Stefan Krebs, Matthias Kimpel, et al. (2014) Wolfgang Schuhmann "Zr-based conversion layer on $\mathrm{Zn}-\mathrm{Al}-\mathrm{Mg}$ alloy coated steel sheets: insights into the formation mechanism", Electrochimica Acta 137: 65-74.

8. Chromating Abdullah Al Mamun, Aina Onoguchi, Giuseppe Granata, Chiharu Tokoro (2018) "Role of $\mathrm{pH}$ in green rust preparation and chromate removal from water", Applied Clay Science 165:205-213.

9. U.S. Patent 5,318,640. H. Ishii et al., (1994) assignors to Henkel Corp., Plymouth Meeting, Pa., "Surface treatment for zinccoated steel sheet” Metal Finishing, Volume 93, Issue 4, April 1995, Page 93.

10. (2018) ASTM B117 - 18, "Standard Practice for Operating Salt Spray (Fog) Apparatus”, ASTM International, USA. 03.02.

11. N. Wint, A. C. A. de Vooys, H. N. McMurray (2016) "The corrosion of chromium based coatings for packaging steel", Electrochimica Acta 203: 326-336.

12. K. Raeissi, M. R. Toroghinejad (2008) "The effect of chromated and organic layers on corrosion resistance of galvanized steel sheets", Progress in Organic Coatings 62:61-64.
13. X. Zhang, W. G. Sloof, A. Hovestad, E. P. M. van Westing (2005) "Characterization of chromate conversion coatings on zinc using XPS and SKPFM", Surface and Coatings Technology, 197:168-176.

14. A. M Rocco, Tania M. C Nogueira, Renata A Simão, Wilma C Lima (2004) "Evaluation of chromate passivation and chromate conversion coating on 55\% Al-Zn coated steel", Surface and Coatings Technology 179:135-144.

15. A Belghazi, S Bohm, J. H Sullivan, D. A Worsley (2002) "Zinc runoff from organically coated galvanised architectural steel”, Corrosion Science, 44:1639-1653.

16. T Prosek, D Thierry (2004) "A model for the release of chromate from organic coatings, Progress in Organic Coatings 49:209-217.

17. Vlastimil Kuklík, Jan Kudláček (2016) Hot-dip galvanized coating formation", Hot-Dip Galvanizing of Steel Structures 29-39.

18. A. Azimi, F. Ashrafizadeh, M. R. Toroghinejad, F. Shahriari (2012) "Metallurgical assessment of critical defects in continuous hot dip galvanized steel sheets", Surface and Coatings Technology 206:4376-4383.

19. S. T. Vagge, V. S. Raja, R. Ganesh Narayanan (2007)“Effect of deformation on the electrochemical behavior of hot-dip galvanized steel sheets", Applied Surface Science 253:84158421 .

20. H. Asgari, M. R. Toroghinejad, M. A. Golozar (2009) "Effect of coating thickness on modifying the texture and corrosion performance of hot-dip galvanized coatings", Current Applied Physics 9:59-66.

21. Eiman Alibakhshi, Alireza Naeimi, Mohammad Ramezanzadeh (2018) "A facile synthesis method of an effective anti-corrosion nanopigment based on zinc polyphosphate through microwaves assisted combustion method; comparing the influence of Nano pigment and conventional zinc phosphate on the anti-corrosion properties of an epoxy coating", Journal of Alloys and Compounds 762:730-744.

22. T.Biestek and J.Weber (1976) Conversion Coatings, Portcullis Press Limited- Redhill, Surrey, 1st Edition.

23. Shigeyoshi Maeda, Masahiro Yamamoto (1998) "The role of chromate treatment after phosphating in paint adhesion", Progress in Organic Coatings 33:83-89.

24. (1995) U.S. Patent 5,318,803. June 7, 1994 H.R. Bickford et al., assignors to International Business Machines Corp., Armonk, N.Y., "Conditioning of a substrate for electroless plating” Metal Finishing 93:93. 
25. (2005) "Corrosion Protection Properties of Organofunctional Silanes-An Overview”, Tsinghua Science \& Technology 10:639-664.

26. W.V.Ooij, M.Stacy, V.Palanivel, A.Lamar and D.Zhu (2002) "The Use of Organofunctional Silanes as a Major Constituent in Organic Coatings for enhanced Corrosion Protection", 13th IFHTSE Congress/International Surface Engineering Congress, Columbus, Ohio, 7:1-9.

27. Thomas Lostak, Christian Timma, Stefan Krebs, Jörg Flock, Stephan Schulz (2016) "Organosilane modified Zrbased conversion layer on $\mathrm{Zn}-\mathrm{Al}$ alloy coated steel sheets", Surface and Coatings Technology 305:223-230.

28. F. J. Shan, C. S. Liu, S. H. Wang, G. C. Qi (2008) "Corrosion resistance of hot dip galvanized steel pretreated with bis-functional silanes modified with nanoalumina, Acta Metallurgica Sinica (English Letters) 21:245-252.

29. W. Trabelsi, E. Triki, L. Dhouibi, M. G. S. Ferreira, M. F. Montemor (2006) "The use of pre-treatments based on doped silane solutions for improved corrosion resistance of galvanised steel substrates", Surface and Coatings Technology 200:4240-4250.

30. Thomas Lostak, Christian Timma, Stefan Krebs, Jörg Flock, Stephan Schulz (2016) "Organosilane modified Zrbased conversion layer on $\mathrm{Zn}-\mathrm{Al}$ alloy coated steel sheets", Surface and Coatings Technology 305:223-230.

31. H. H. Sheu, H. B. Lee, S. Y. Jian, C. Y. Hsu, et al. (2016) "Investigation on the corrosion resistance of trivalent chromium conversion passivate on electroplated Zn-Ni alloy", Surface and Coatings Technology 305:241-248.

32. Robert Berger, Ulf Bexell, T. Mikael Grehk, Sven-Erik Hörnström (2007) "A comparative study of the corrosion protective properties of chromium and chromium passivation methods", Surface and Coatings Technology 202:391-397.

33. A Barbucci, M Delucchi, G Cerisola (1998) "Study of chromate-free pretreatments and primers for the protection of galvanised steel sheets", Progress in Organic Coatings 33:131-138.

34. Indumathi S.N, T. Vasudevan, S. Sundarrajan, B. V. Subba Rao, C.V.S.Murthy D.R.Yadav (2011) "Cadmium- and chromate-free coating schemes for corrosion protection of 15CDV6 steel", Metal Finishing $109: 15-21$.

35. Gang KONG, Jintang LU, Haijiang WU (2009) "Post treatment of silane and cerium salt as chromate replacers on galvanized steel", Journal of Rare Earths 27:164-168.

36. G.D.Wilcox and D.R.Gabe (1998) "Chemical Molybdate Conversion Treatments for Zinc", Metal Finishing 71-74.

\section{Submit your manuscript to a JScholar journal} and benefit from:

ฯ Convenient online submission

ฯ Rigorous peer review

q Immediate publication on acceptance

ๆ Open access: articles freely available online

I High visibility within the field

I Better discount for your subsequent articles

Submit your manuscript at http://www.jscholaronline.org/submit-manuscript.php 